أثر استخدام روابط الحتوى (التوسعية - البسيطة) في كتب الواقع المعزز في تنمية

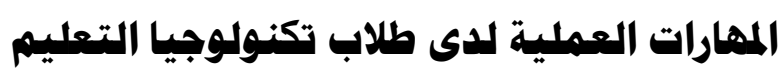

أ.د / محمد زيدان عبد الحميد

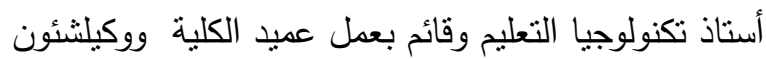

التعليم والطلاب كلية التربية النوعية - جامعة المنوفية.

م.م/ سماء عبد السلام حجازي

مدرس مساعد بقسم تكنولوجيا التعليم والحاسب الآلئي، كلية

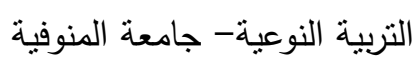

أ.د. وليد يوسف محمد

أستاذ تكنولوجيا التعليم

كلية التربية _ جامعة حلوان

أ.م.د. عبد القادر عبد المنعم صالح

استاذ تكنولوجيا التعليم المساعد المتفرغ

كلية التربية النوعية جامعة المنوفية.

مستخلص البحث

هدف البحث الحالي إلى الكثف عن أثر اختلاف مستوى روابط المحتوى (التوسعية-

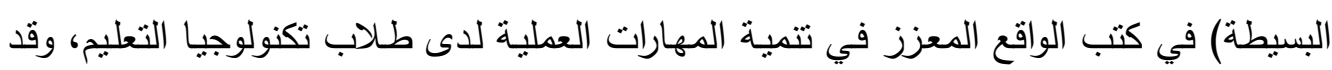
تم عرض مشكلة البحث ومنهجيته، وأهدافه وخطواته، واستخدم البحث المنهج الوصفي (المسح

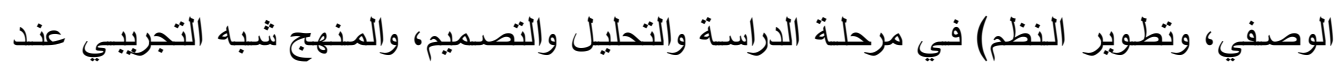
قياس أثر المتغير المستقل للبحث على المتغيرات التابعة في مرحلة التقويم، وذلك من خـلال

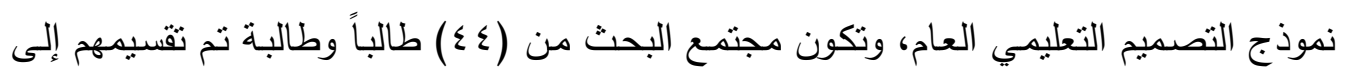

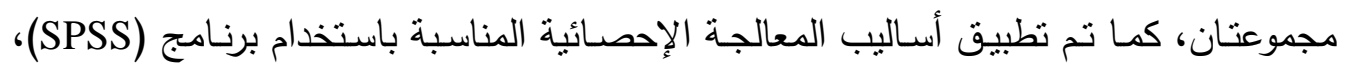
وتوصلت الباحثة إلى مجموعة من النتائج والتي من أهمها:

الكتاب المعزز بغض النظر عن تأثثر نوع روابط المحتوى ( التوسعية- البسيطة) له

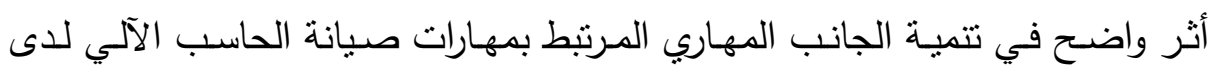
طلاب تكنولوجيا التعليم والحاسب الآلي.

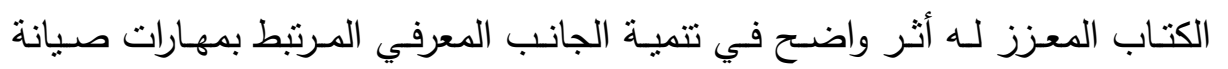
الحاسب الآلي لدى طلاب تكنولوجيا التعليم والحاسب الآلي.

الكلمات المفتاحية Keywords: الواقع المعزز - الكتاب المعزز - روابط المحتوى التوسعية والبسيطة - - - المهارات العملية. 


\section{Summary of the research}

The aim of the current research is to reveal the effect of the different level of content links (expansive - simple) in augmented reality books in developing practical skills for educational technology students. The research problem, , methodology, importance and steps were presented. The research used the descriptive approach (Descriptive survey and systems development) in the study, analysis and design phase, and the quasi-experimental approach when measuring the effect of the independent variable of the research on the dependent variables in the evaluation phase, through the general educational design model, and the research community consisted of 44 students who were divided into tow groups. and appropriate statistical treatment methods were applied using the (SPSS) program, and the researcher reached a set of results, the most important of which are:

- The augmented book has a clear impact on the development of the skills aspect related to computer maintenance skills for students of education technology and computer.

- The augmented book has a clear impact on the development of the knowledge side related to the skills of computer maintenance for students of education technology and computer.

Keywords: augmented reality - augmented book - expansionary and simple links - practical skills. 
تشهد تكنولوجيا التعليم تطوراً كبيراً خلال الآونة الأخيرة بفضل مستحدثات تكنولوجيا التعليم واتصـالها الوثيق بـالتطور الكبير في مجال الاتصسالات والهواتف والأجهزة الذكية والتطبيقات المرتبطة بها، والتي كان لها أثر واضتح في تطور تقنيات التعليم والإستراتيجيات التعليمية بما يتلاعم مع التطور الحادث للوصول إلى مخرجات تعلم أفضل مما كانت عليه. ومن المستحدثات الحالية تقنية الواقع المعزز ، ويعتبر لتقنية الواقع المعزز دوراً فعالاً في التي تحسين إدراك المتعلمين والفهم الأعمق للمعلومة وذلك ما وضحه كل من (جارزون وآخرون،

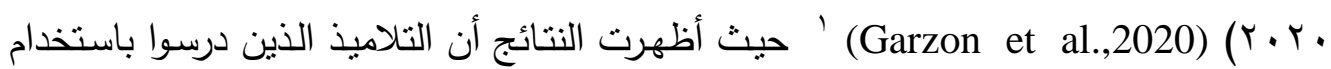

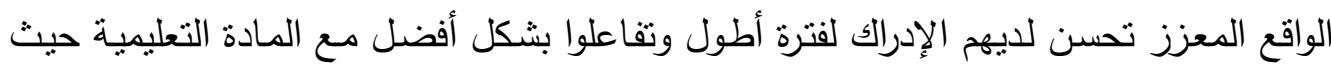
تضـيف تقنيـة الواقع المعزز بعداً إضـافياً جديداً لتدريس هذه المفاهيم مقارنـة بطرق التدريس باستخدام الوسائط الأخرى. وتعد تقنية الواقع المعزز أحد أهم تطبيقات استخدام الحاسب الآلي والأجهزة الذكية، ويدخل فيها الصوت والصورة الثابتة والمتحركة ذات الأبعاد الثنائية أو الثالثية كنواة أساسية في أسلوب المحاكاة. ويعد الواقع المعزز أحد التكنولوجيات التي تجذب انتباه الباحثين والمصدمين في مجالات تفاعل الإنسان مع الكمبيوتز، مما بسمح بإجراء تجارب تعليمية ذات مغزى، وترتكز على طرق موضوعية لايصال المعرفة، والتركيز على التتمية الفكرية والعاطفية للمشاهد، حيث أن أحدث وجهات النظر تؤكد أن بيئات التعلم بـالواقع المعزز لديها القدرة على تقديم قيمة عالية لكل من الن البيئات التعليمية والترفيهية (Lee, 2012).

ولقد استخدمت تكنولوجيا الواقع المعزز لتطوبر تطبيقات تعليمية وترفيهية متعددة. فهي تسمح للمستخدم بتجربة الواقع ولكنه معزز بمحتوى كمبيوتري معد مسبقاً ومدمج مع الحقيقة، والمستخدم هنا لا يستعرض المحتوى فقط ولكنه يتفاعل معه أيضاً. وقد ظهر الكتاب المعزز كأحد التطبيقات لتقنية الواقع المعزز والذي يمثل Pop-ups books حيث يسمح للمستخدم بروئية محتوى ثلاثي الأبعاد كما تسمح بالتفاعل (Tang, 2004). وفي المجال التعليمي تتقل تطبيقات الواقع المعزز الطالب إلى عالم المعلومات الدراسية ليختبر أسسها ومسبباتها بنفسه في خبرة واقعية بدلاً من التعامل مع هذه المعلومات في قالب نصي ثابت. حيث يتم الإطلاع على كافة المعلومات الدراسية في إطار محفز ومشوق يجمع مئرة

'استخدمت الباحثة نظام توثيق جمعية علم النفس الأمريكية الإصدار السابع (Association, APA 7

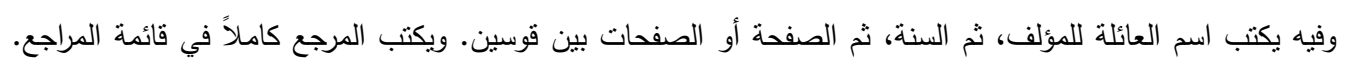
هذا بالنسبة للغة الأجنية، أما المراجع العربية تكتب الأسماء بالكامل كما هي معروفة في البيئة العربية. 
بين نقل المادة العلمبة وإبهار الواقع المعزز الذي ينتقل إلبه التلاميذ وتعزيز التقنية للفهم

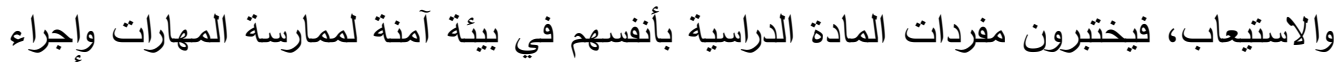
التجارب، مما يوفر درجة عالية من التفاعل الذاتي، ويحسن أسلوب التواصل والتفاعل. مما سبق نجد أن هناك مبررات لاستخدام تكنولوجيا الواقع المعزز في التعليم منها الالتزام

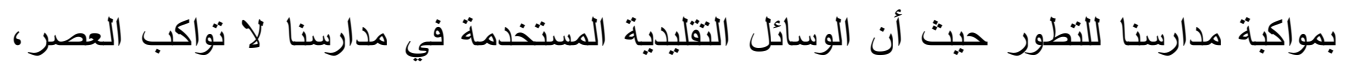

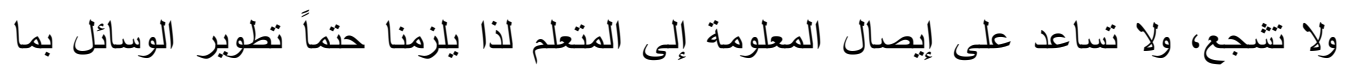
يتتاسب مع العصر الذي نعيش فيه لاسيما هذه التقنيات التي تساهم في رفع الإنتاجية للمعلم والمتعلم.

ويعد من أهم تطبيقات الواقع المعزز في التعليم كتب الواقع المعزز ففي الآونة الأخيرة

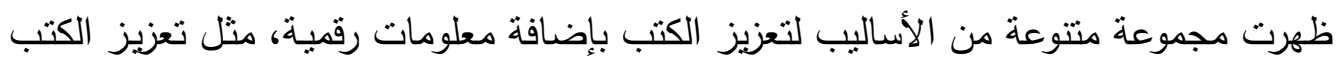
الورقية بكائنات افتراضية ثلاثية الأبعاد باستخدام تقنية الواقع المعزز (cho et al., 2010).

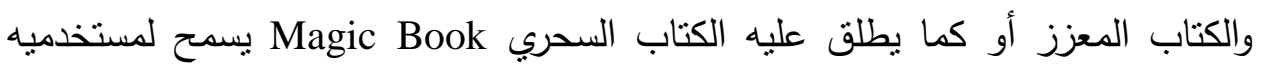

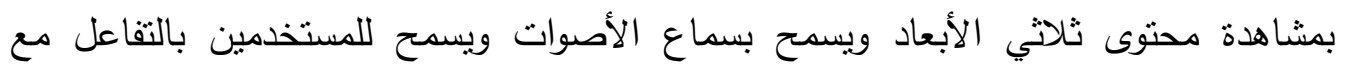
المحتوى المعزز، وهذا ما جعل الكتاب المعزز يجذب انتباه الباحثين وكذلك المتعلمين لما له له

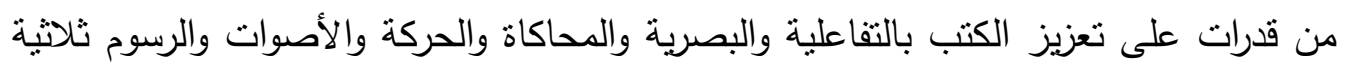

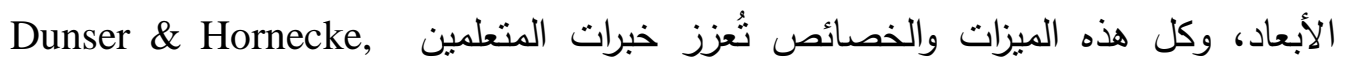

وبذلك أصبح الكتاب المعزز محط اهتمام من الباحثين كوسيلة لتعزيز الكتب التقليدية بمصورات ورسومات متحركة وصور ثلاثية البعد وأصوات ومحاكاة للواقع مما يجعل المتعلم

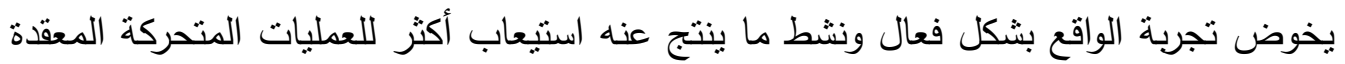

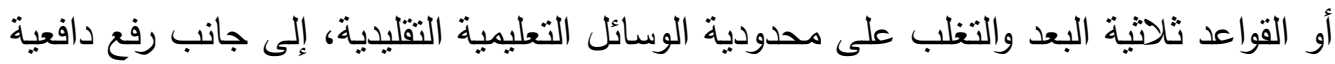
التعلم ودفع التشاركية ودعم إثرائية العملية التعليمية. ولكي تتحقق الإفادة من تطبيقات الواقع المعزز في الكتب المعززة في تحقيق نواتج التعلم

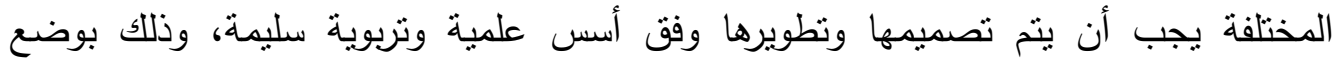
إجراءات تحكم عملية تصميمها وتطويرها، وتوفير قاعدة تتظيمية تحكم مراحل تصميمها وتطويرها، ووضع ضوابط أساسية تساعد على اختبار أنسب الطرق التي تساعد على تصميم

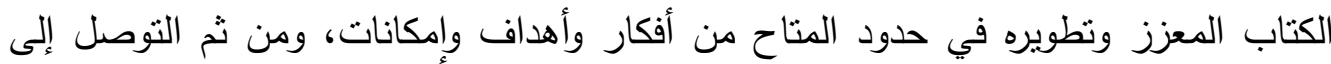
إستراتيجيات مقتنة تستند إليها قرارات تصميم هذه الكتب وتطويرها، وتكون مستمدة من تكامل البحوث التي تنتاول متغيراً أو أكثر من متغيرات تصميم هذه الكتاب بوصفها تمنل المواصفات

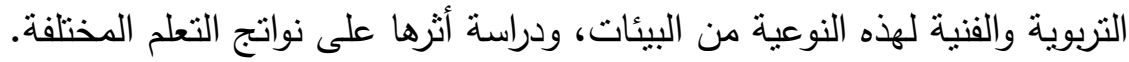


وتعد روابط المحتوى من أهم أدوات اكتساب المعلومات في عديد من بيئات التعلم الإكترونية، فالبحث والتصفح من الأنشطة التي يقوم بها المتعلم للبحث عن معلومات فلثمات محددة،

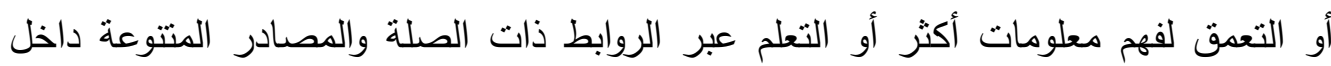
المحتوى الإككتروني (Brusilovsky, 2001; Stash, 2007).

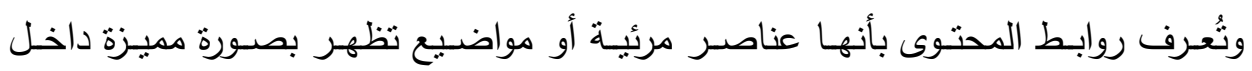

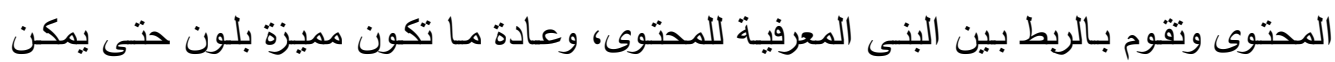

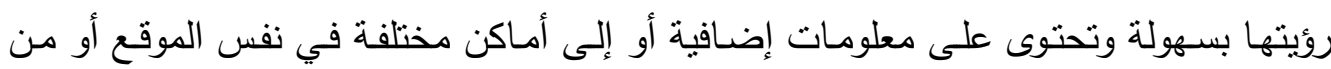

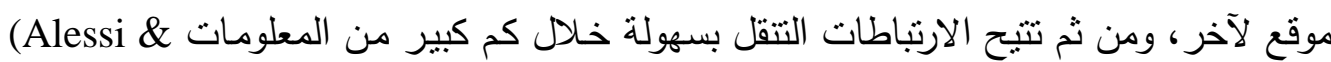

Trollop, 2001; Tsandilas, 2003; Ko \& Rossen, 2008; Deitel \& Deitel, 2008). وتعتمد فاعلية روابط المحتوى البصرية على مجموعـة من العوامل والتي بدورها تمثل التل

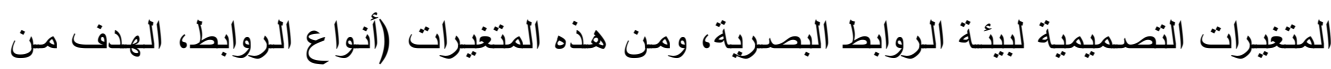

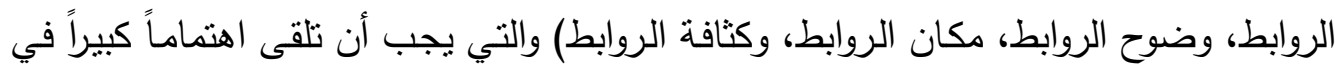

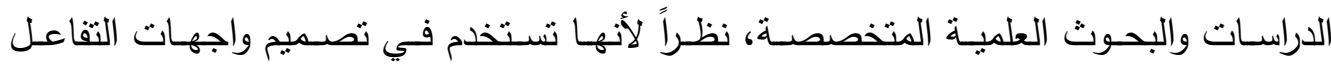

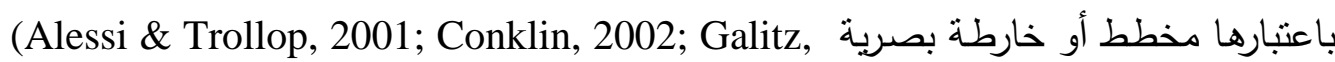
2007; Wang et al., 2009). وتقوم الروابط البصرية اللفظية وغير اللفظية البصرية وفقاً لنظرية المرونة المعرفية والتي

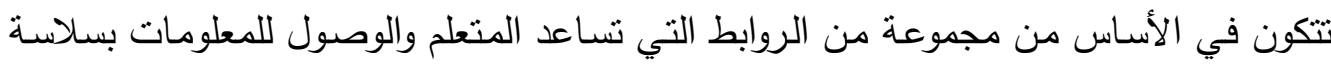

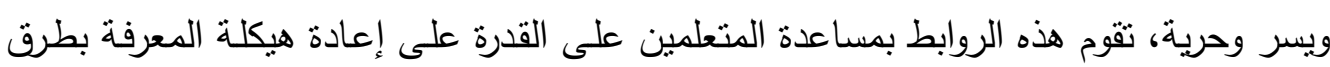

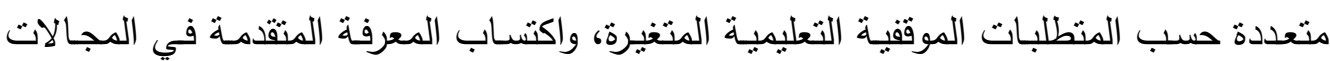

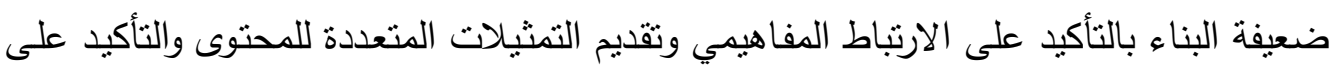

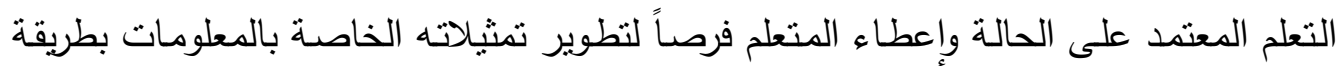
ملائمة (Spiro et al., 2004). وفي هذا الإطار يعد تعلم المهارات العملية بجانبيها الأدائي والمعرفي أحد نواتج التعلم الأساسية التي يمكن أن تعكس- في كثير من الأحيان - الصورة الحقيقية لمدى فاعلية البيئات

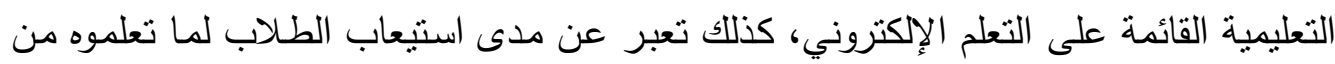

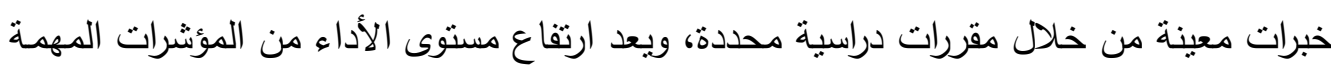

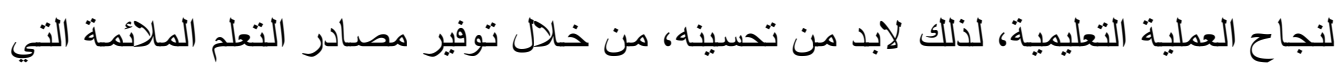
تساعد على ارتفاع مستوى الأداء (Stecher, 2010).

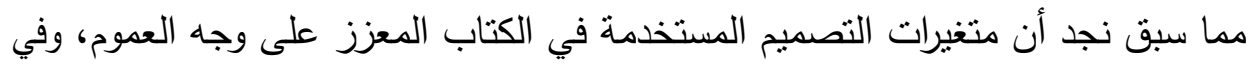
الروابط على وجه الخصوص، قد تؤثر بشكل مباشر على أداء الطلاب لبعض الهُ المهارات العملية. 
وفي ضوء ما سبق اتجهت الباحثة في دراستها الحالية إلى البحث في كيفية تحسين كفاءة

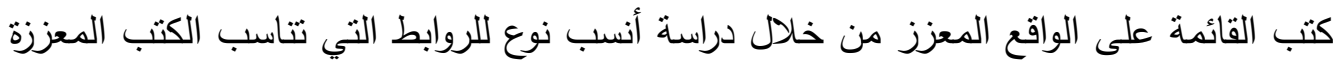

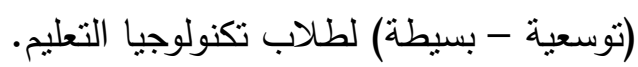

\section{مشكلة البحث:}

تعد مهارات صيانة الحاسب الآلي من المهارات العملية والتي يصعب على الطلاب

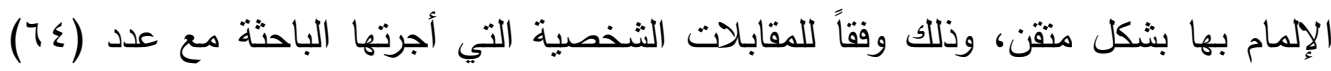

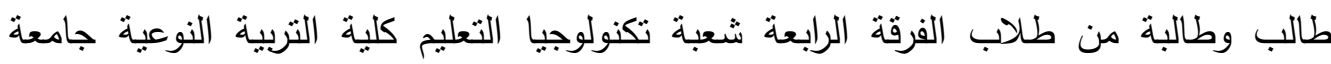

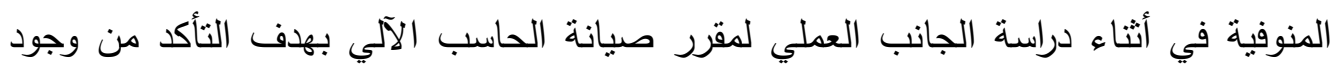

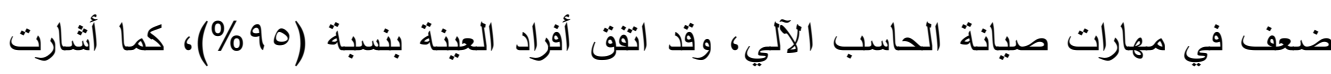

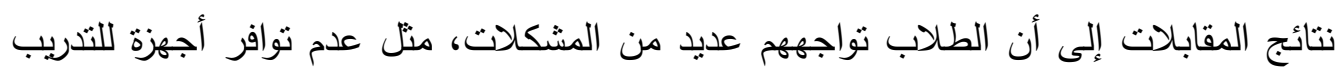

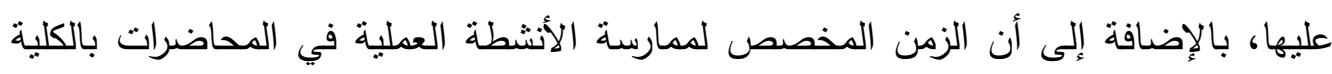

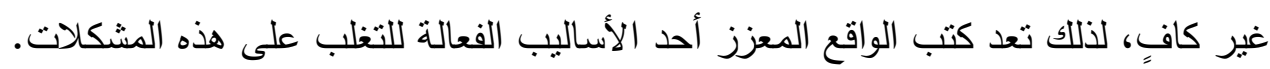

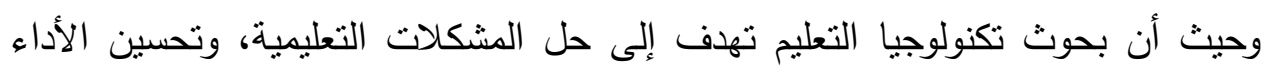
والممارسات التكنولوجية التعليمية، وتحسين نواتج التعلم عن طريق المستحدثات التكنولوجية

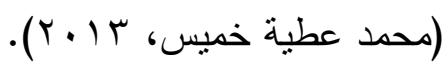
ومن المستحدثات الحالية تقنية الواقع المعزز، ويعتبر لتقنية الواقع المعزز دوراً فعالاً في تحسين إدراك المتعلمين والفهم الأعمق للمعلومة وذلك ما وضحه كل من جارزون وآخرون

(Garzon et al.,2020)

لذللك تم استغلال المستحدثات التكنولوجية وتضمينها في التعليم الإلكتروني كتكنولوجيا الواقع المعزز وما ينبثق منها من تقنيات الواقع المعزز ككتب الواقع المعزز لتسهيل عملية التعلم على المتعلمين وجعلها أكثر إثارة وتشويق.

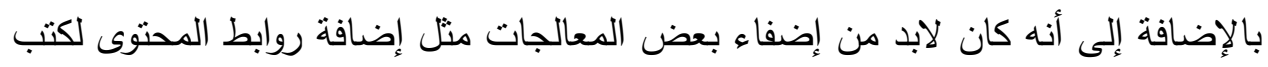

$$
\text { الواقع المعزز بنوعيها (التوسعية - البسيطة). }
$$

إلا أن أغلب البحوث التي نوالت في تصميم كتب الواقع المعزز ومعالجتها لم تلتقب

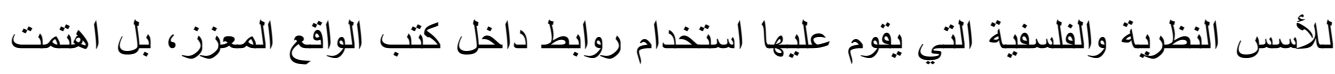

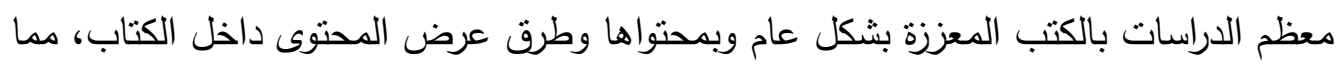

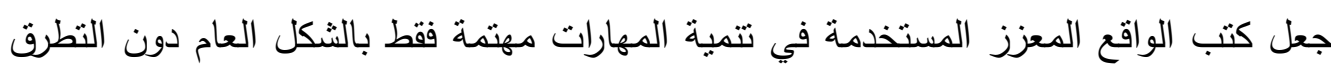
لتفاصيل تصميم الكتاب وروابط المحتوى بداخله. 
كما استشعرث الباحثة مشكلة البحث من خلال مراجعة البحوث السابقة، ويمكن توضيح

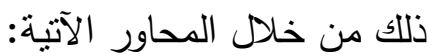

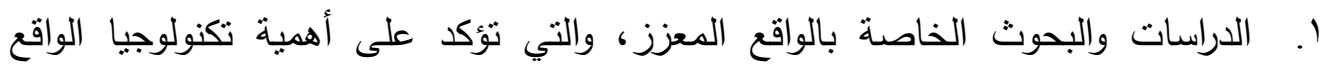

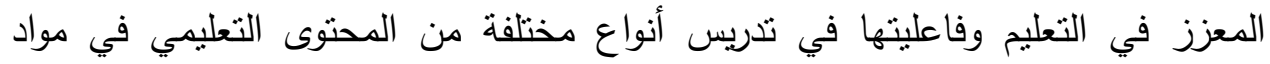

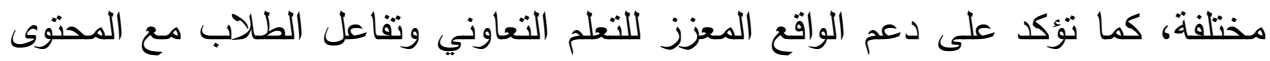

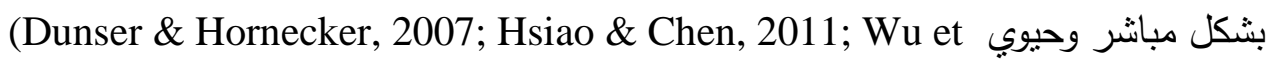
al., 2013; Rodgers ,2014).

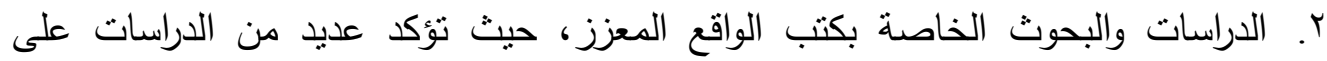

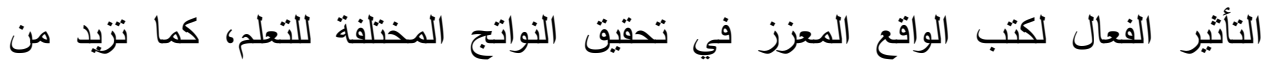

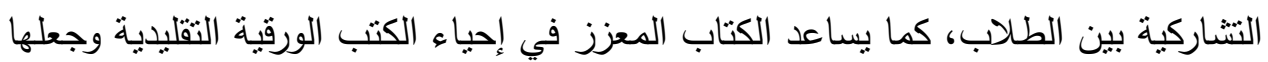

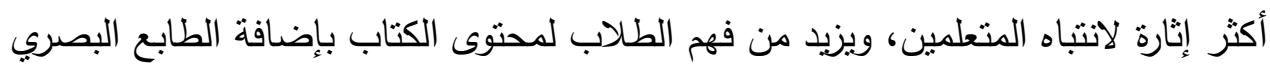

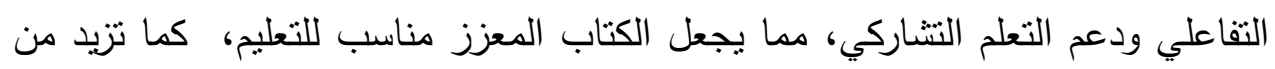
دافعية الطلاب للتعلم (Dunser \& Hornecke, 2007; Taketa et al., 2007; Yusoff et al., 2015; Inagawa \& Fujinami, 2008; Rahman et al., 2011; Abas \& Zaman, 2011).

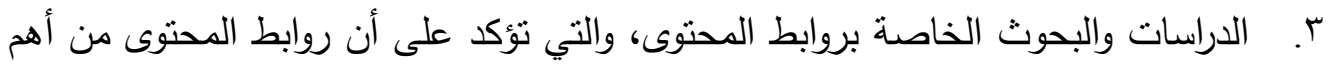
أدوات اكتساب المعلومات، والتعمث لفهم معلومات أكثر ، والتعلم عبر الروابط ذابط ذات التهات الصلة،

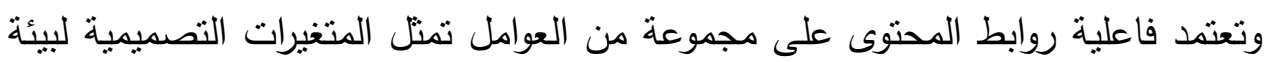

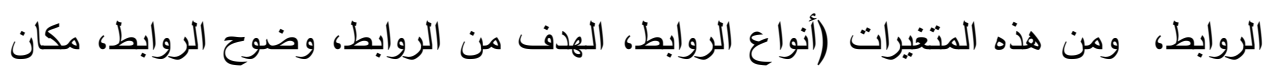

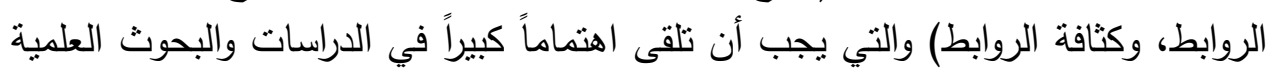

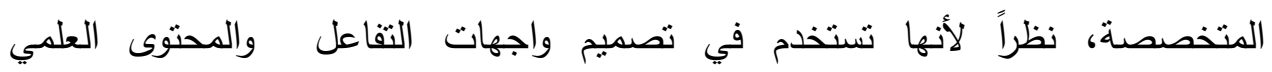
(Brusilovsky, 2001; Stash, 2007; Ignacio et al., 2001; Conklin, 2002; Galitz, 2007; Wang et al., 2009). فتحاول الباحثة في الدراسة الحالية باستخدام روابط المحتوى البسيطة والتوسعية في كتب

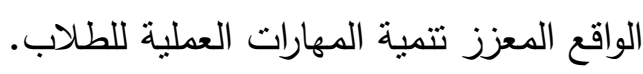
وفى هذا الإطار يعد تحقيق أكبر فائدة ممكنة من سعة الكتب المعززة من أهم أهداف

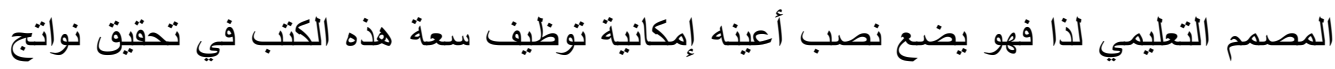

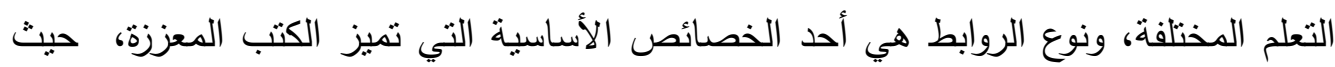
تستخدم الروابط المتاحة في ضبط مسار المتعلم للتوغل في العمق المعرفي لمحتوى الكتاب المابط

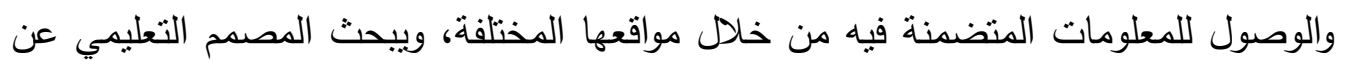

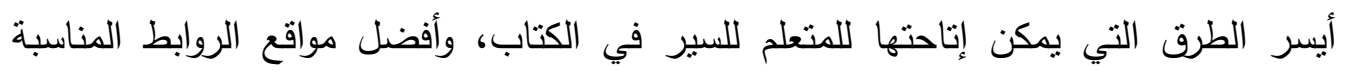
لتحقيق هذا الهدف. 
وعلى ضوء ما سبق يمكن بلورة مشكلة البحث وصياغتها في العبارة التقريرية التالية:

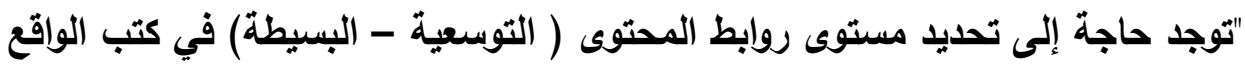
المعزز على تنمية المهارات العملية لدى طلاب تكنولوجيا التعليم".

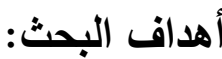
يهدف البحث الحالي إلى: 1. تحديد المهارات الأساسية لمقرر الصيانة اللازمة لطلاب قسم تكنولوجيا التعليم.

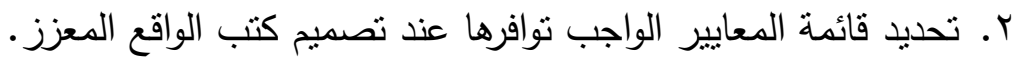

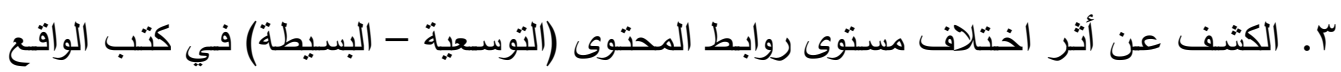
المعزز في تتمية المهارات العملية لاى طلاب تكنولوجيا التعليم. ع. تحديد أنسب مستوى لروابط المحتوى (التوسعية- البسيطة)، عند تقديم المحتوى من خلال

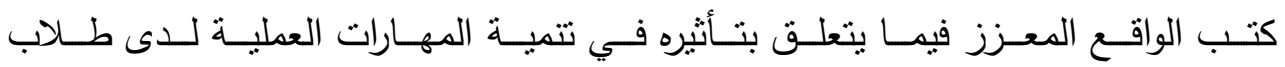
تكنولوجيا التعليم. منهج البحث: ينتمي هذا البحث إلى فئة البحوث التي تستخدم المنهج الوصفي(المسح الوصفي - تطوير

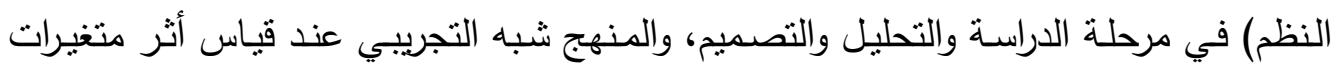
البحث المستقلة على متغيراته التابعة في مرحلة التقويم. خطوات البحث: البح:

لتحقيق أهداف البحث، اتبعت الباحثة الخطوات التالية:

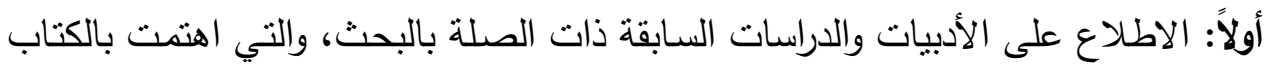
المعزز والروابط (التوسعية- البسيطة) والمهارات العملية.

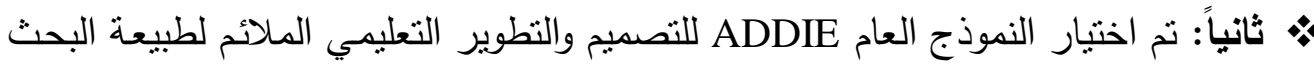
الحالي والعمل وفق إجراءاته المنهجية. ثالثاً: تم صياغة الأهداف الإجرائية الخاصـة بالمحتوى العلمي الذي تم اختياره، وعرضها

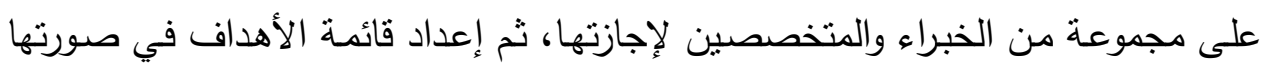

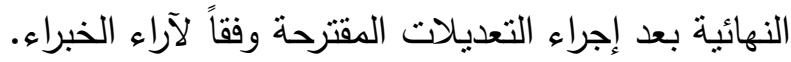

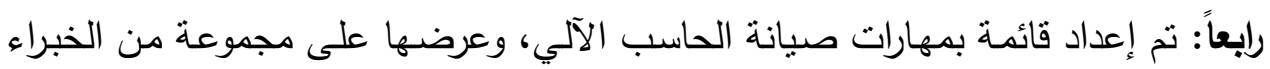

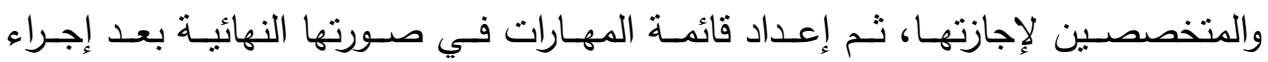

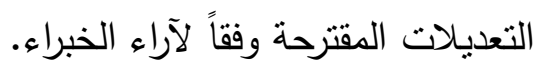


خامسـاً: تم تحليل المحتوى العلمي لمهارات صيانة الحاسب الآلكي وتتظيمه في ضوء

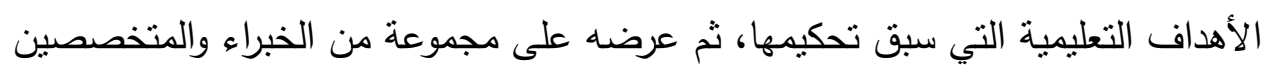

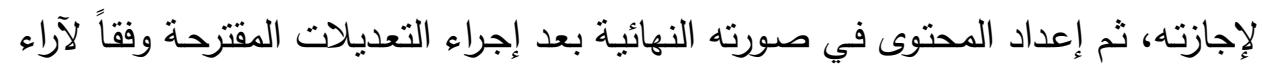
الخبراء. سادساً: تم إعداد قائمة بمعايير تصميم الكتاب المعزز بالروابط (التوسعية- البسيطة)، ثم عرضها على مجموعة من الخبراء والمتخصصين، وإجراء التعديلات المطلوبة.

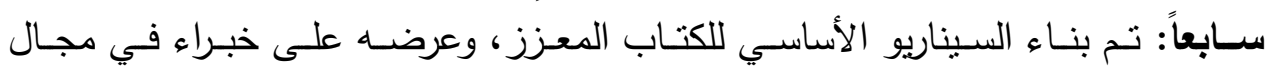

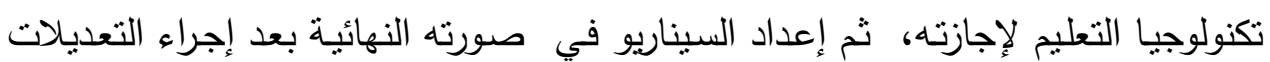
المقترحة وفقاً لآراء السادة المحكمين. ثامناً: تم إنتاج الكتاب المعزز بالروابط (التوسعية- البسيطة)، ثم عرضهاء على خبراء في مجال تكنولوجيا التعليم لإجازته ثم إعداد المعدل في صورته النهائية بعد إجراء التعديلات المقترحة وفق آراء السادة المحكمين.

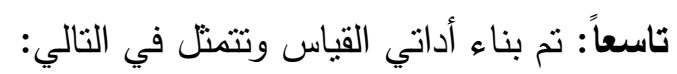
م الاختبار المعرفي لقياس الجانب المعرفي المرتبط بمهارات صيانة الحاسب الآلكي،

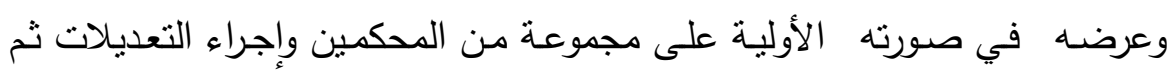

$$
\text { إعداده في صورته النهائية. }
$$

o بطاقـة ملاحظة لقياس الجانب الأدائي المـرتبط بمهارات صبيانة الحاسب الآلي،

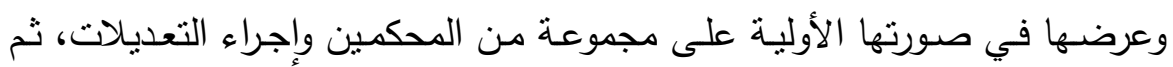

$$
\text { إعدادها في صورتها النهائية. }
$$

عاشراً: تم إجراء تجربة الدراسة الاستطلاعية وتطبيق أدوات الدراسة، وذلك بهدف تجريب

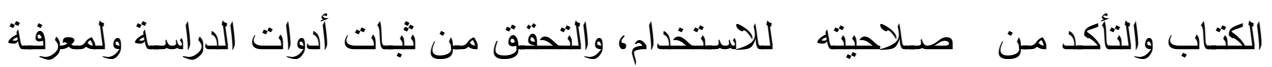
الصعوبات التي قد تواجه الباحثة أو أفراد عينة البحث عند إجراء التجربة الأساسية للبحث.

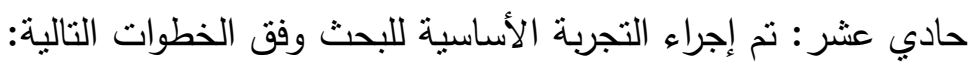

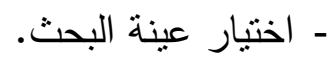
- تطبيق أدوات القياس قبلياً. - توزيع مجموعتي البحث وفقاً للتصميم التجريبي للبحث. - ت ت تفيذ التجربة الأساسية. - تطبيق أدوات القياس بعدياً. 
ثاني عثر : تم إجراء المعالجات الإحصـائية اللازمة لقياس أثر استخدام روابط المحتوى

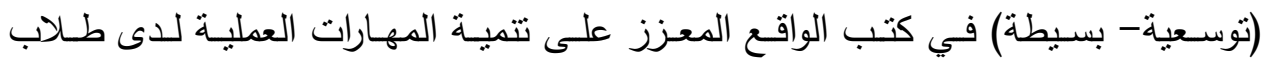
تكنولوجيا التعليم. ثالث عشر : تم عرض النتائج وتفسيرها ومناقثتها في ضوء الدراسات والبحوث السـابقة ونظريات التعليم والتعلم. رابـع عشـر : تم تقديم مجموعـة مـن التوصـيات والمقترحسات في ضـوء النتـائج التي تم التوصل إليها.

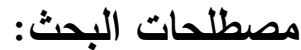

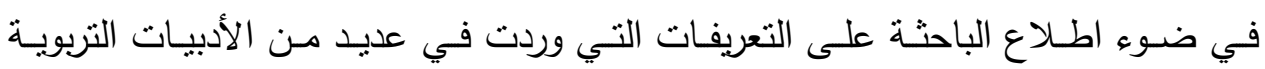

والنفسية ذات العلاقة بمتغيرات البحث تم تحديد مصطلحات البحث إجرائياً على النحو الأتي: > كتب الواقع المعزز: وهو عبارة عن كتاب عادي مزود بعلامات للواقع المعزز كواجهة

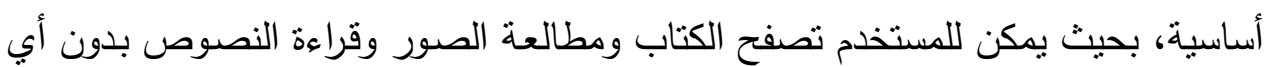

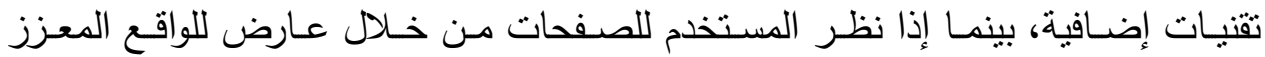
(الهاتف الذكي) فسيظهر كائنات افتراضية لقطات فيديو أو رسومات ثنائية وثلاثية الأبعاد، ويُعتبر ذلك طريقة مثيرة للاهتمام لنقل المستخدم بين الواقع والافتراضية باستخدام كائن

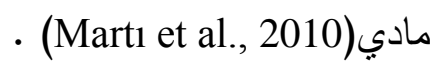
ويُعرف إجرائياً في البحث الحالي بأنه: عبارة عن كتاب ورقي مزود بصور ضمن المحتوى

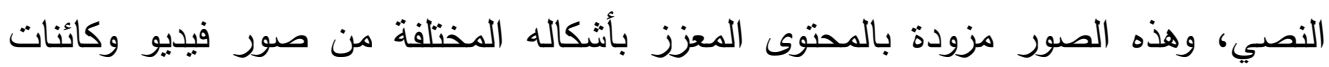

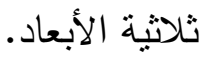
> روابط المحتوى: تعرف إجرائياً في هذا البحث بأنها أيقونات تظهر من خلال الكتاب

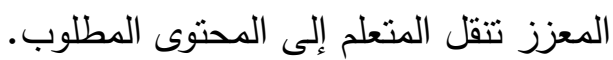
> الـروابط التوسـية: تعرف إجرائياً في هذا البحث بأنها أكثر مـن رابط يظهر للمتعلم

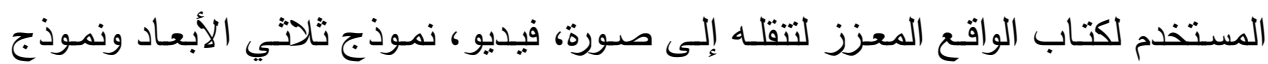
محاكاة كلٍ على حدى برابط مستقل. > الروابط البسيطة: تعرف إجرائياً في هذا البحث بأنها رابط أساسي واحد فقط قد يحتوي

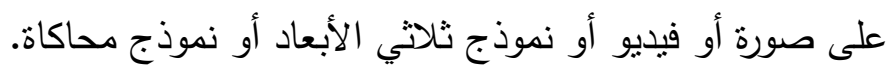

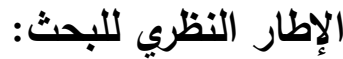

في ضوء طبيعة وأهداف البحث الحالي نم عرض الإطار النظري من خلال الدحاور التالية: 


\section{المحور الأول: كتب الواقع المعزز Augmented book.}

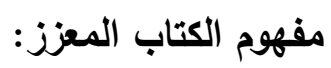

كما يطلق عليه كلٍ من يوين وآخرون (2011) الكتاب السحري ويعرفوه بأنه "واجهة لنظام يسمح لأي كتاب عادي أن ينشأ بتقنية الواقع المعزز ، مما يعطي الكتاب حياة

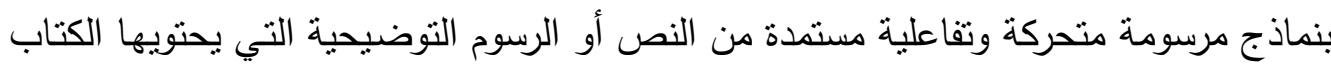

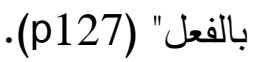

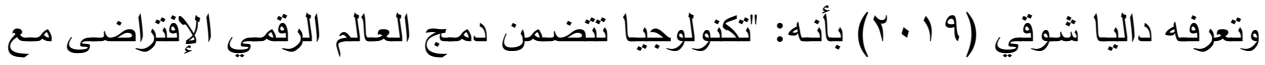

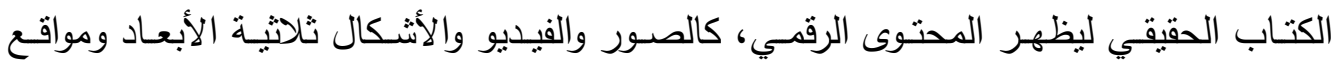

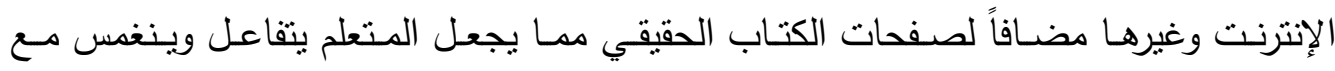
المحتوى الرقمي" (ص. ع ؟ب).

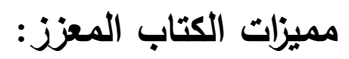

يمكن للكتاب المعزز أن يزيد من فهم مستخدميه للمحتوى ويُعزز الانطباعات البصرية

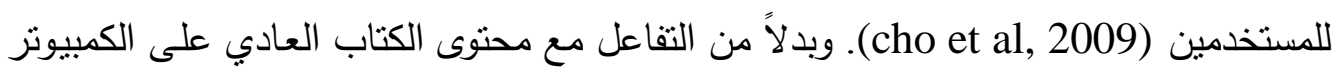

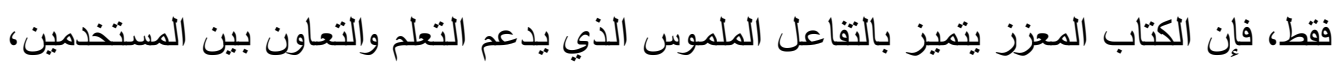

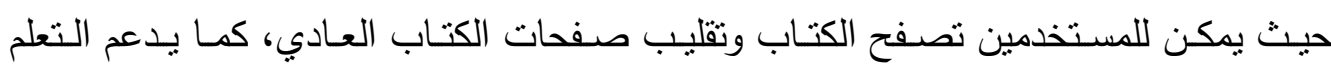

التعاوني (Dunser \& Hornecker, 2007). وفي ذات الإطار تؤكد عديد من الدراسات على التأثير الفعال لكتب الواقع المعزز في

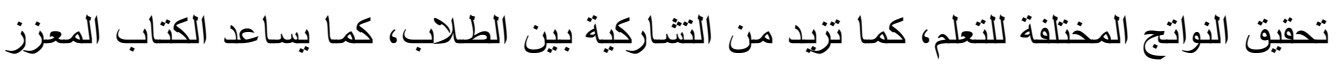

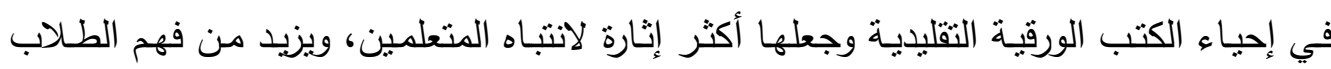

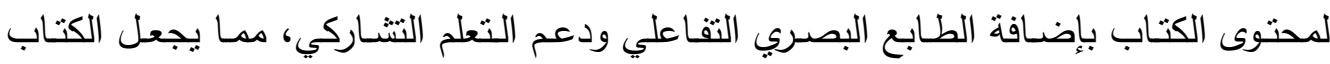

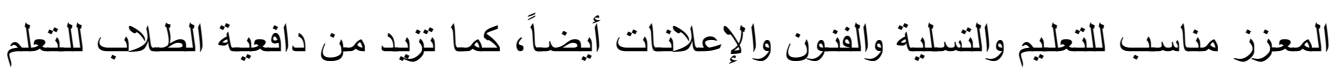
(Dunser \& Hornecke, 2007; Taketa et al., 2007; Yusoff et al., 2015; Inagawa \& Fujinami, 2008; Rahman et al., 2011; Abas \& Zaman, 2011)

$$
\text { استخدام الكتب المعززة في البحث الحالي: }
$$

يعد مقرر صيانة الحاسب الآلي من المقررات ذا محتوى يعتمد بشكل أساسي على العى العي

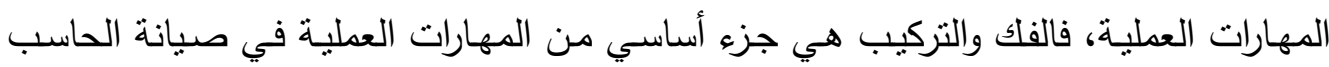

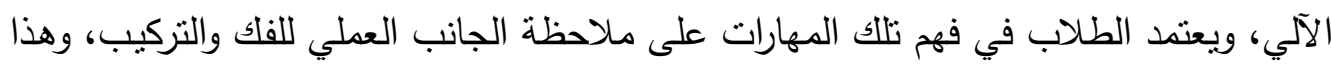

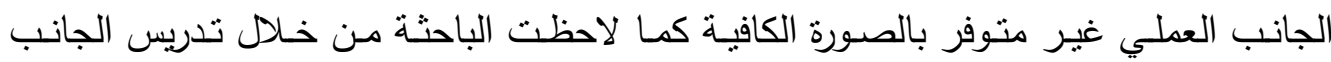
العملي لمادة الصيانة. 
أظهرت العديد من الدراسـات المختلفة أهميـة الواقع المعزز بشكل عام والكتب المعززة

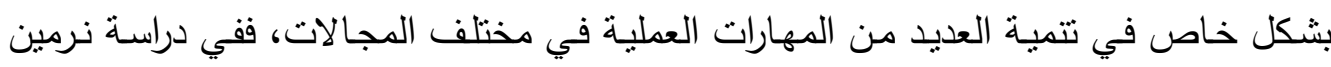

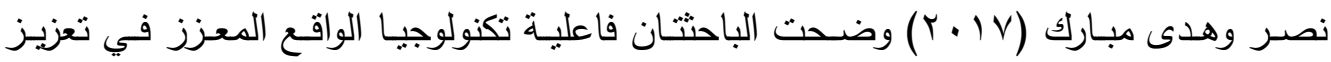

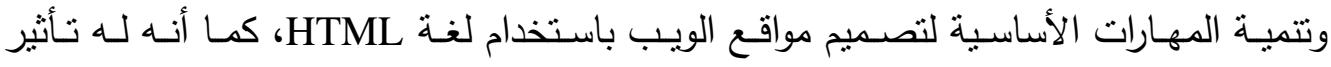

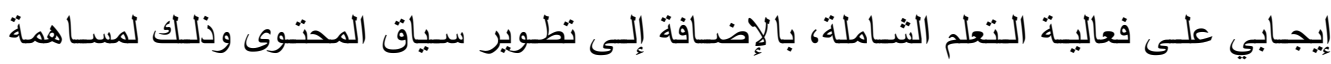

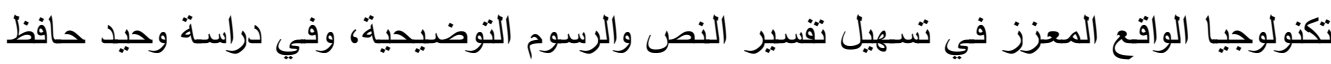

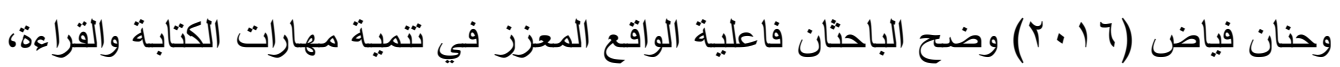

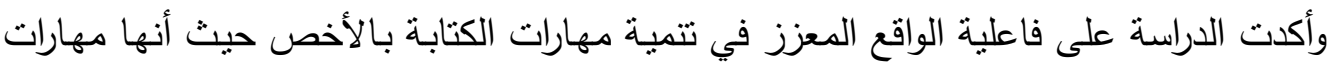

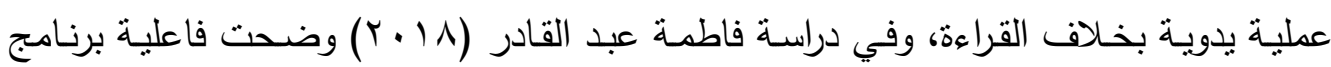
قائم على تقنية الواقع المعزز في تتمية الجانب الأدائي للمهارات العملية، وفي دراسـة عبد الحليم

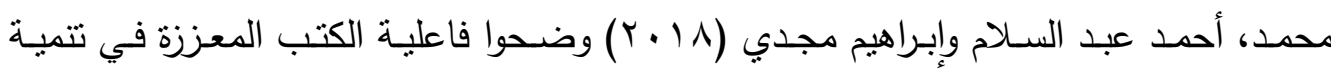

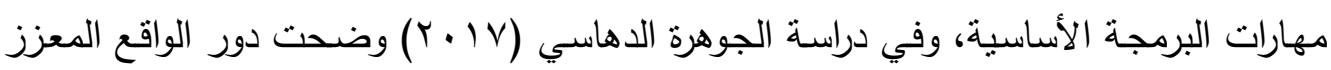
في تتمية مهارات التقكير الرياضي.

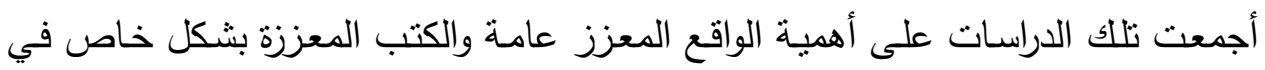

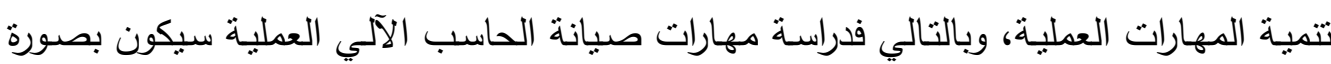
فعالة أكثر في صورة كتاب معزز بالصور والفيديو والكائنات ثلاثية الأبعاد.

\section{تكنولوجيات إنتاج الكتب المعززة:}

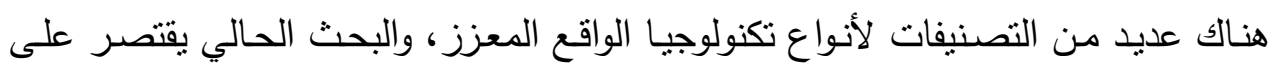

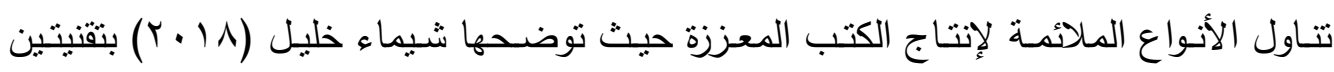
لتصميم الواقع المعزز وهما:

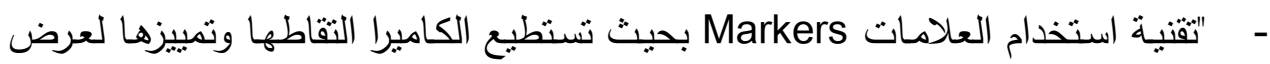

المعلومات المرتبطة بها، وفي هذه الحالة يسمى الواقع المعزز القائم على العلامة.

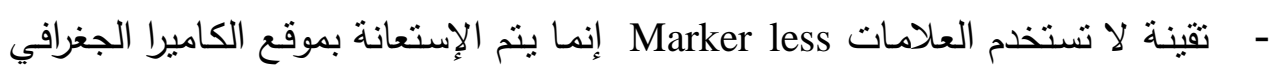

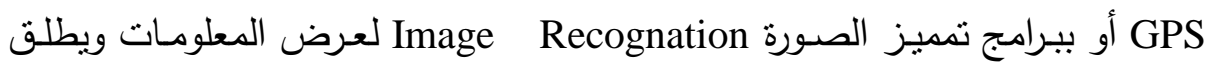
عليه الواقع المعزز القائم على الصورة. لئميز وتختلف طرق تتبع العلامات وهي علامة ثنائية الأبعاد مبرمجة لإظهار محتوى رقمي

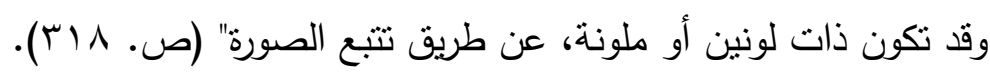

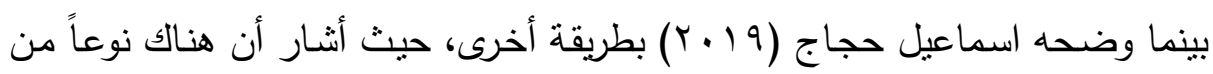
الواقع المعزز متاحان حالياً للمعلمين وهما: 


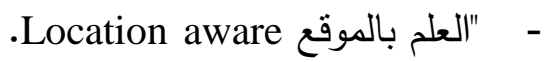

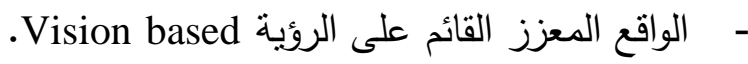
حيث يقدم النوع الأول وسـائط رقميـة للمتعلمين تتحرك بهم خـلال المنطقة الماديـة وذلك باستخدام الهاتف الذكي تمكين GPS مـن تحديد المنطقـة المتواجد بهـا المـتعلم وتقديم معلومات على شكل وسائط متنوعة ( نصوص - رسوم - صوت - فيديو ) والنماذج ثلاثيـة فئن

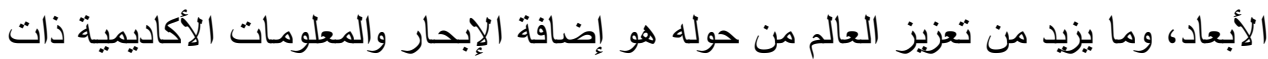

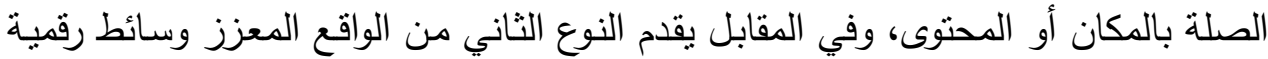

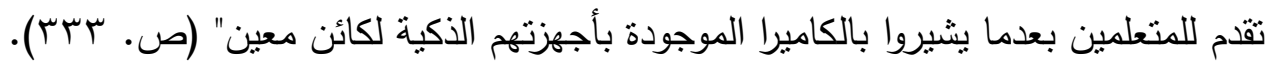

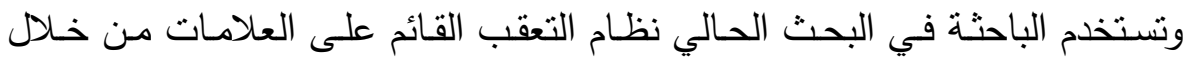

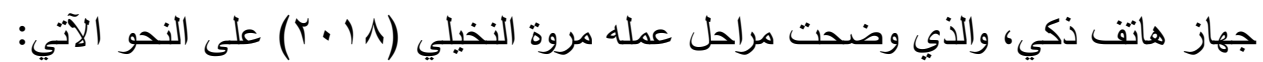

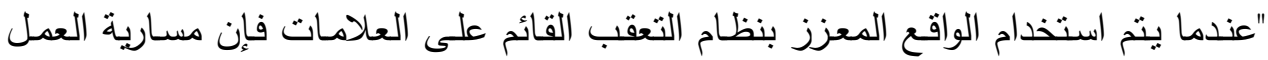

$$
\text { تتكون من ثلاث مراحل أساسية وهي: }
$$

- مرحلة التعرف Detect: وفيها يتم التعرف على الصورة من خلال التعرف على نقاط محددة AR fiducial متضمنة داخل الصورة على صفحة الكتاب تمثل رموز العالم المادة كنقطة مرجعية للكمبيوتر •

مرحلة التببع Tracking: يقوم كمبيوتز مقدم الخدمة بتقسير الرمز (AR fiducial)

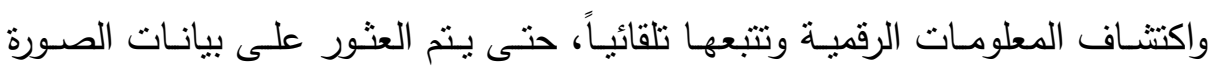

نفسها. - مرحلة التوليد والدمج Display \& Integrate: يرسل المخدم عبر التطبيق ملف رقمي لجهاز المستخدم فيتم نوليد طبقة من مشهد افتراضي قد يكون صورة أو فيديو أو رسم ثلاثي الأبعاد على شاشة جهاز المستخدم" (ص.0).

$$
\text { إنتاج الكتب المعززة في البحث الحالي: }
$$

أثنارت الكثير من الدراسات والبحوث لبرامج وتطبيقات مختلفة خاصة بإنتاج بيئات التعلم القائمة على الواقع المعزز ومن هذه التطبيقات والبرامج:

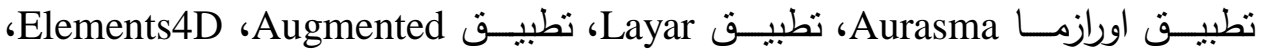
Anatomy 4D وبالرغم من إتاحة هذه التطبيقات وتطويرها ومجانيتها، إلا أنها لم تلائم منطلبات البحث الحالي، لذا لجأت الباحثة لبرمجة الكتاب المعزز ببرامج عدة على على النحو الآتي: 
- - برنامج Unity 3D، وهو عبارة عن محرك ألعاب متعدد المنصـات استخدم البحث الحـالي منصـة فيفوريـا Vuforia ، والتـي جعلت إنثـاء محتوى الواقع المعزز أكثر

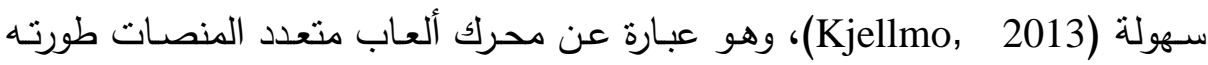
شركة Unity Technologies، بدعم مستويات مختلفة من التعقيد ليناسب مستويات المطورين (Smith et al., 2019) واستعانت الباحثة بمبرمج لإنتاج النطبيق ببرنامج

.Unity

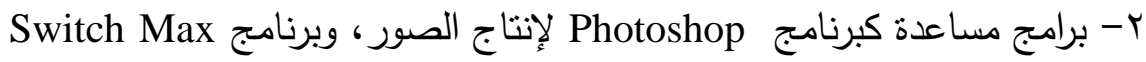

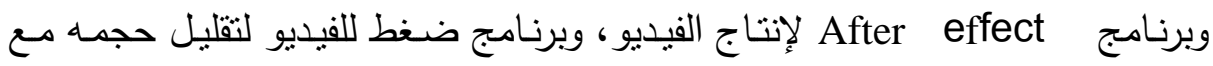
الحفاظ على جودته، وذلك حتى لا يكون المنتج النهائي ذو حجم كبير يصعب تداوله

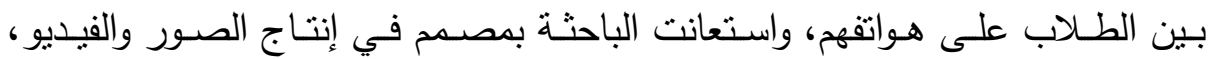
وقامت الباحثة بضغط الفيديو.

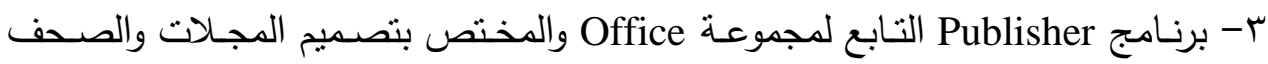
والكتب، استخدمته الباحثة في تصميم كتاب الواقع المعزز الورقي، وراعت في إنتاج

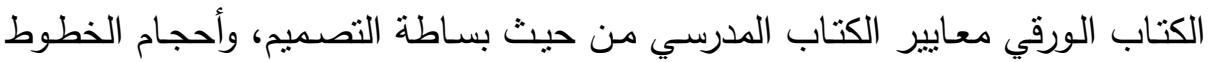

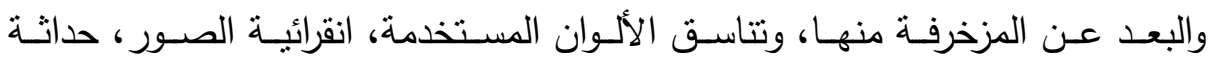

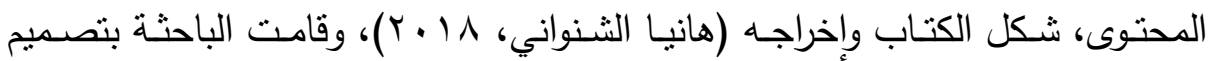
الكتاب وتعديله على البرنامج وطباعته.

معايير تصميم الكتاب المعزز وإنتاجه:

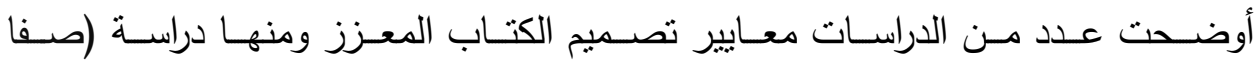

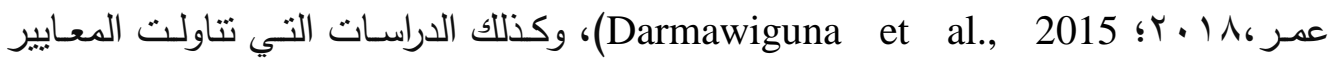

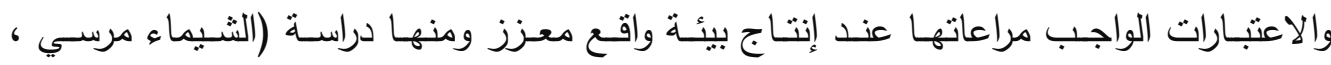
$\cdot(r \cdot) 1$ ولإعـداد قائهـة المعـايير التـي سـوف يتت على أساسـها تصـيم الكتاب المعزز وإنتاجـه، إطلعت الباحثة على تلك المراجع والدراسـات الخاصـة بمعايير الكتب المعززة والبيئات القائهـة

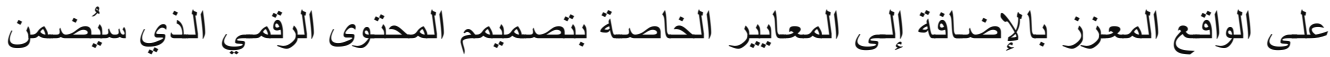

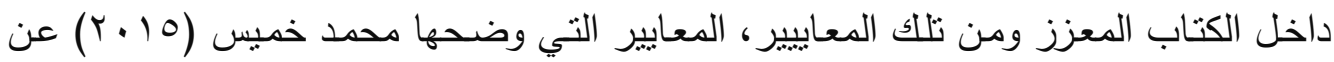
معايير جودة المحتوى الإكتروني، ومعـايير تصـيم محتوى المقررات التعليمية الإلكترونيـة، والتي استعانت بها الباحثة في المعايير الخاصة بالئرون بالمحتوى العلمي. وفيما يلي عرض لأهم ما جاء بنلك الدراسات والمراجع من المعايير التي اعتمدت عليها الباحثة: بالئه: 


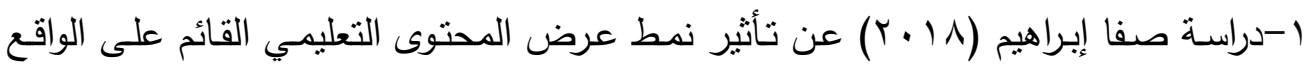

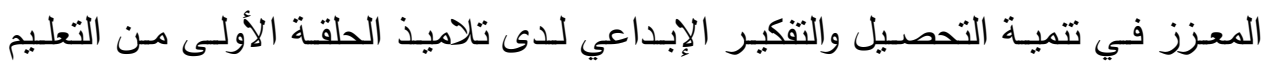

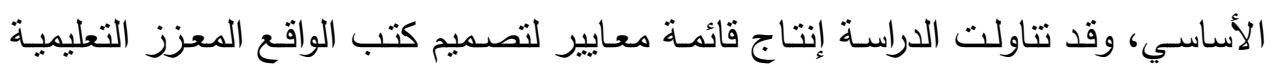
واهتمت في قائمة المعايير بما يلي: -

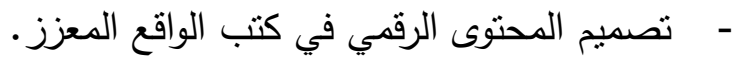
- - تصميم عناصر الوسائط المتعددة في كتب الواقع المعزز .

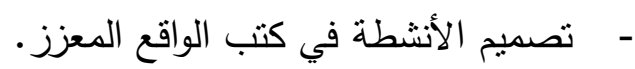
- - - تصميم التقويم في كتب الواقع المعزز. -

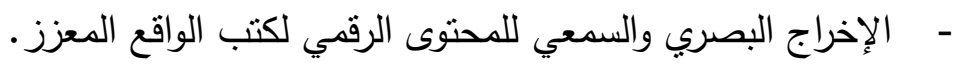

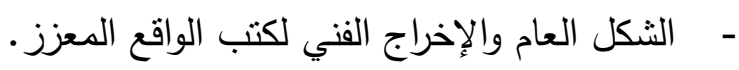
- - اختيار تطبيقات الواقع المعزز المناسبة.

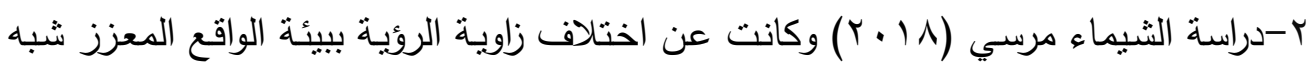

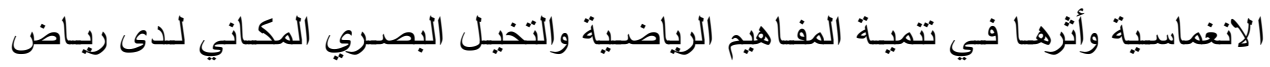
الأطفال واهتمت قائمة المعايير بما يلي: - الاهتمام بمعايير التوثيق. - - مراعاة خصائص الأطفال والاهتمام بالأهداف التعليمية المناسبة لهم. - الاهتمام بنظام العرض والروئة الجيدة وأدواته.

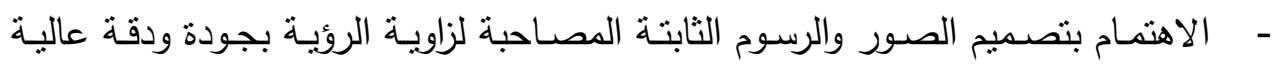

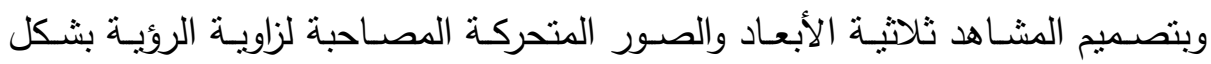

مناسب لتحقيق الفاعلية. - ضبط الألوان المعروضة ومراعاة انعكاس الضوء. - - تصميم الصوت والموسيقى والمؤثرات الصوتية المناسبة للهوف. - - تتمية المفاهيم الرياضية، والتخيل البصري المكاني.

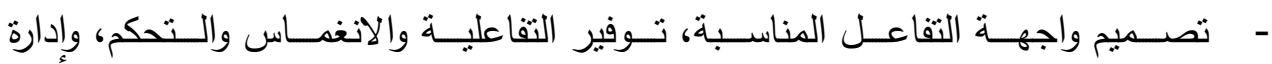
التعلم بالبيئة.

ب-معايير تصميم محتوى المقررات التعليمية الإلكترونية (محمد خميس، 10 ـ ب):

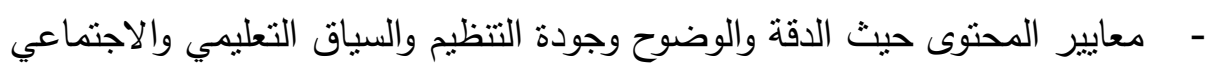


- معايير الإبحار حيث الإبحار التعليمي والمساعدة الإجرائية وتتبع المتعلم.

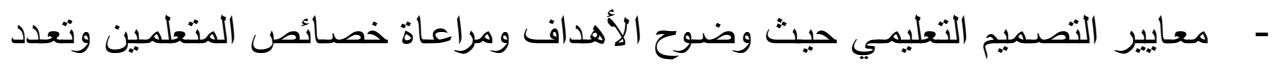

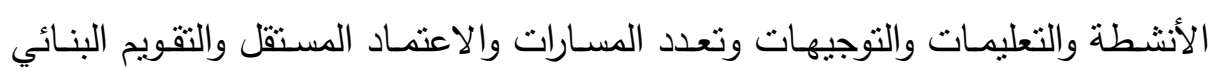

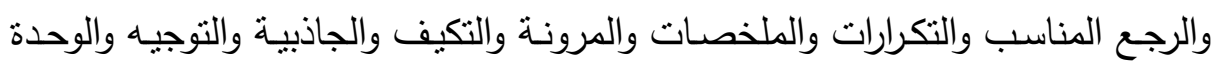

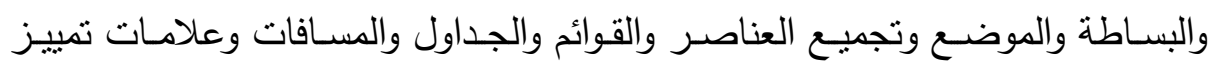
النصوص والنوازن والتتاسق واستخدام الألوان. - معايير الوسائط التعليمية حيث تصميم الوسائط وواجهة التفاعل وعناصر الوسائط. المحور الثاني: روابط المحتوى (التوسعية - البسيطة) في كتب الواقع المعزز. مفهوم روابط المحتوى: - مكئ

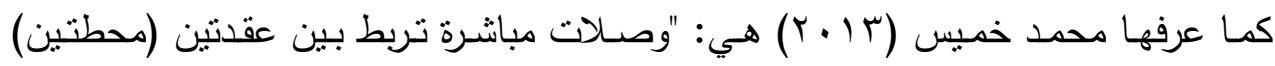
بينههـا علاقـة مشتركة في المحتوى أو المعنى، تسمى العقدة الأولى عقدة المصدر (محطـة

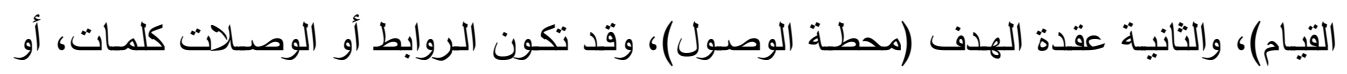

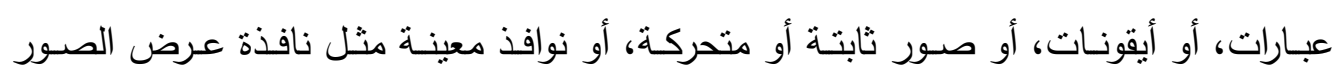
المتحركة، أو أي شئ Object آخر يمكن اختياره بالنقر على الفأرة وتظل الوصلة ساكنة حتى ابتى

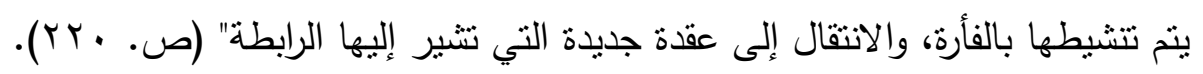

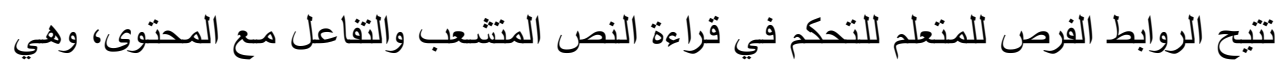

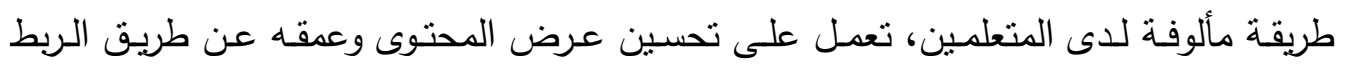
بمعلومات إضافية عالية الجودة، وربط القارىء بالمحتوى المناسب في الموقع مباثرة، وقد تكون

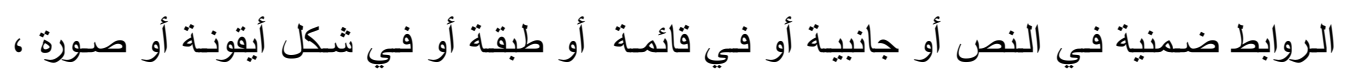
ويجب أن تكون الروابط واضحة، وإلا فلن ينتبه إليها القارئ، ولأن هذه الروابط هي التي تحكم حركة القارئ في التتقل واستكثاف المعلومات، لذلك يجب تصميم هذه الروابط على وأسى أسـاس

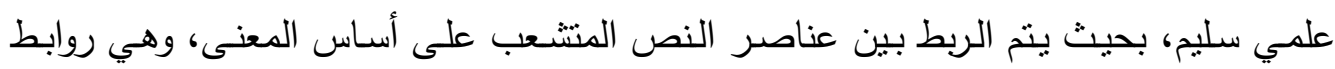
تأخذ القارئ إلى أماكن مختلفة في نفس الموقع أو في مواقع أخرى (محدد خميس، 10 بـ ب). ولترتيب مستوى هذه الروابط وتحديد كثافتها داخل المحتوى يجب على الباحثة الرجوع إلى في إنى

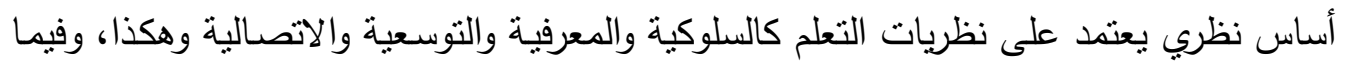
يلي عرض لربط بعض النظريات بمسنوى الروابط (بسيطة - توسعية). 
نمطي الروابط موضع المتغير المستقل للبحث الحالي:

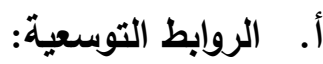

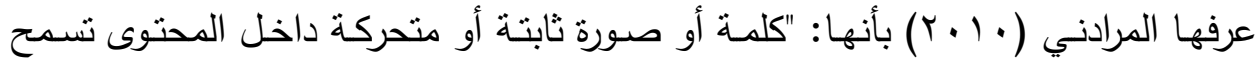

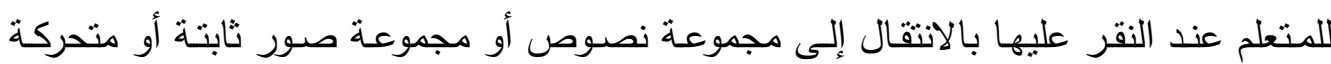

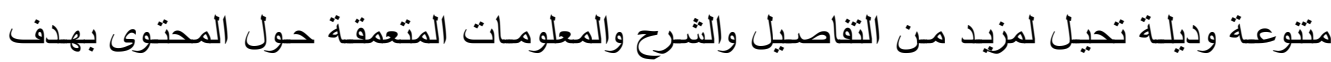

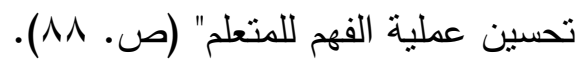
وهنـا يتفقق مـع هـذا التوجـه نحسو اسـتخدام الـروابط التوسـعية بصـفة عامـة عـدد مـن

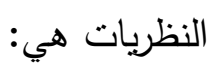

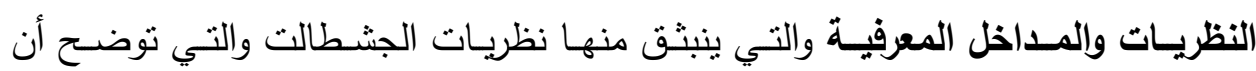
السلوك الإنساني عبارة عن وحدة كلية غير قابلة للتحليل، والإدراك هو محور النظرية؛ حيث ينت

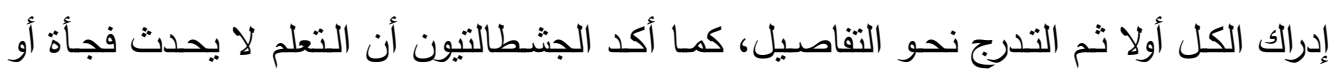

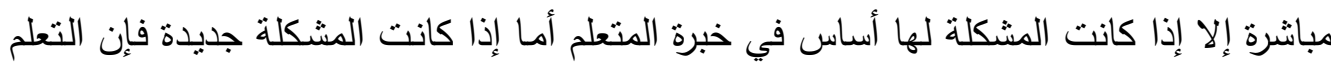

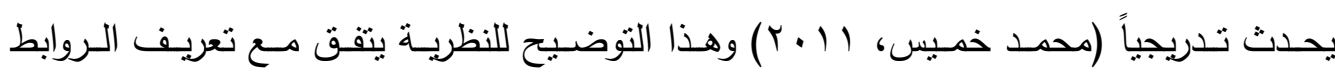

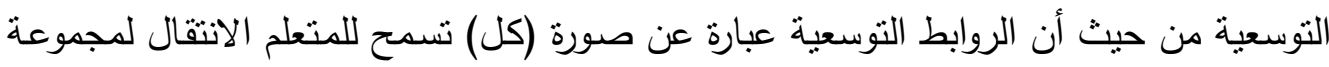
نصوص أو مجموعة صور ثابتة أو متحركة ومزيد من التفاصيل (الأجزاء).

Theory The Elaboration وفي إطار النظرية الجشطالتية تظهر النظريـة التوسعية لرايجلوث والتي نتبثق من المدرسة الجشطالتية والتي تقوم على ثلاثة افتراضات رئيسة حيث يبدأ

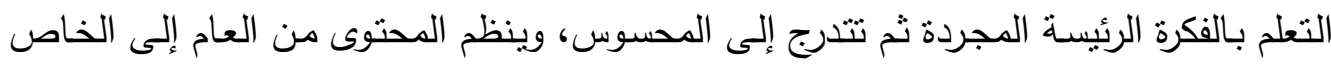
وفق مراحل تبدأ بفكرة عامـة ثم تقصيل للمحتوى مـع الربط بين العناصـر المختلفـة وتتنتهي

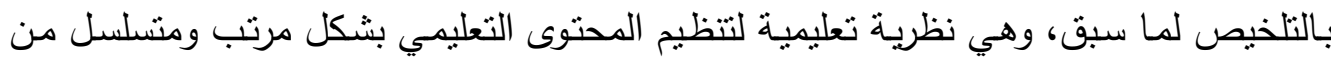

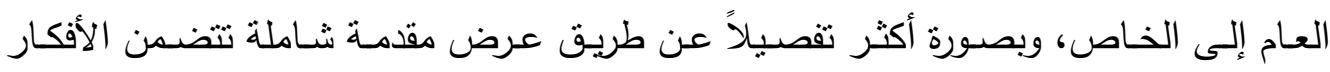

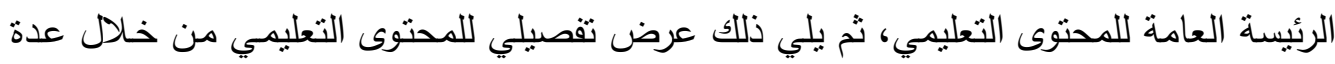

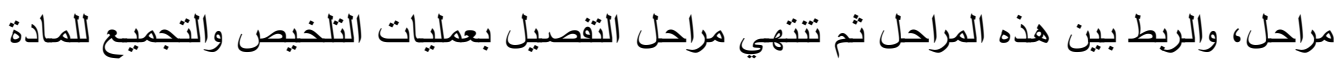

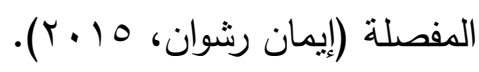

ويتفق مع هذا التوجها أيضـا نظريـة المجال ويقصد بالمجال سلوك الفرد والتعلم من خلال هذه النظرية هو التغير في سلوك الفرد وبنيته المعرفية نتيجة لتأثثر كل هذه القوى والموجهات

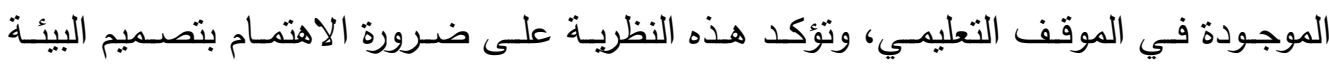


التعليمية أو الموقف التعليمي بطريقة نساعد على حدوث هذا السلوك والنظر إليها نظرة كلية

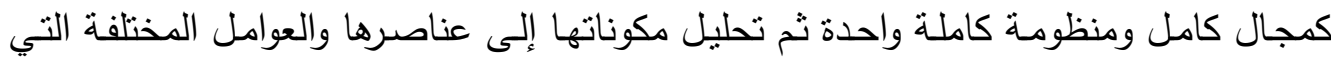

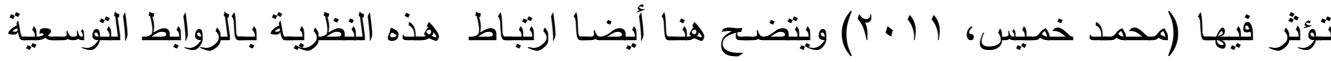

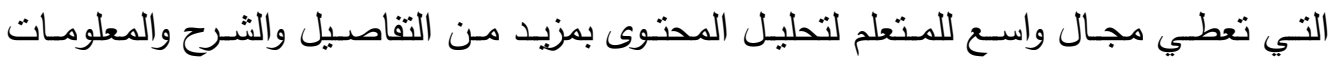
المتعقة حول المحتوى بهدف تحسين عملية الفهم للمتعلم.

Social Information Processing كذلك يؤيد هذا التوجه نظريـة معالجة المعلومـات والتي ترى أن التعلم عملية معرفية توصف بأنها تغير في المعرفة المخزنة في (SIP) Theory

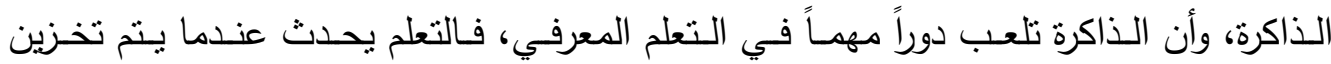

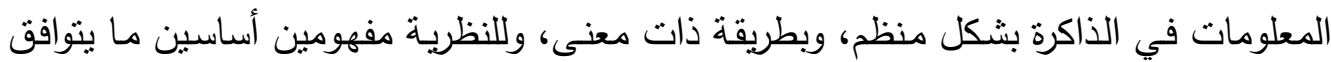

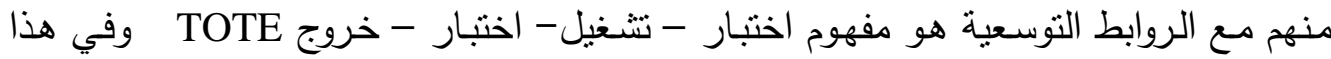

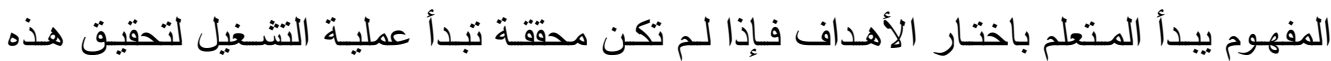

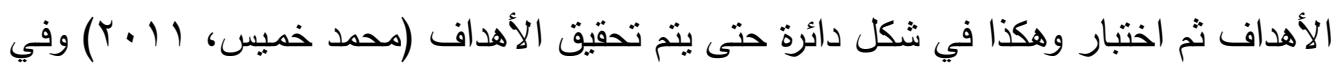

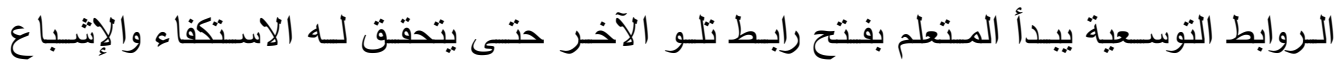
وتحقيق الأهداف.

تأتي بعد ذلك نظرية الحمل المعرفي Cognitive Load Theory وهي نظرية تهدف إلى إلى

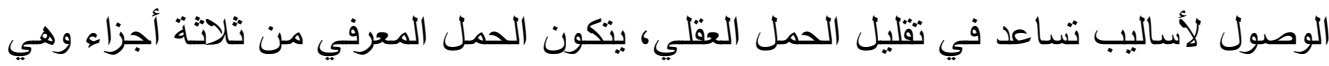

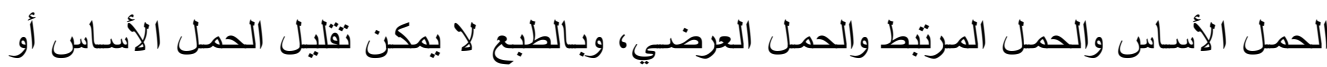

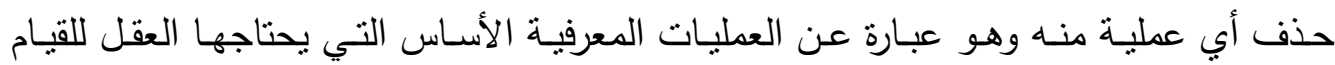

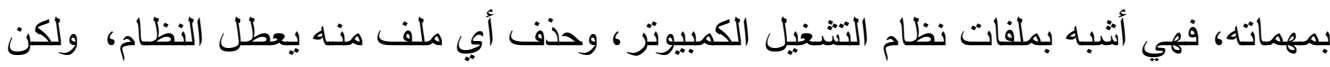

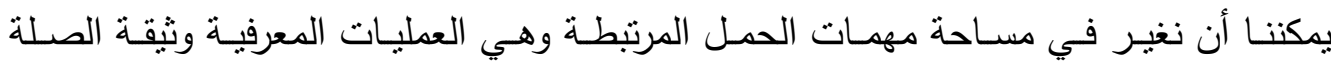

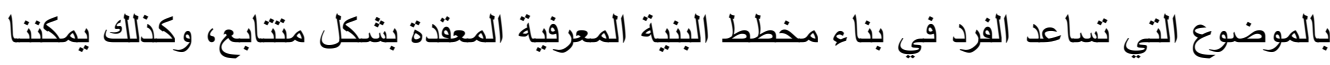

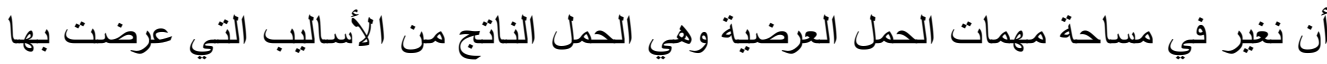

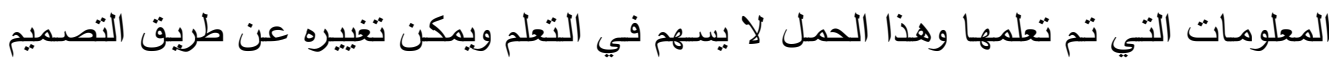

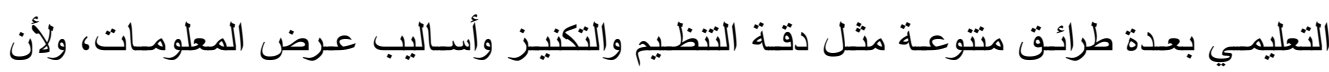

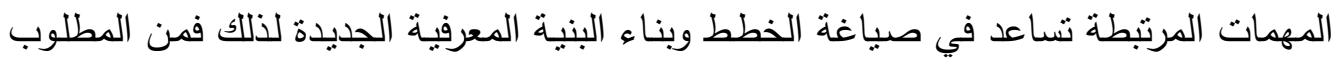

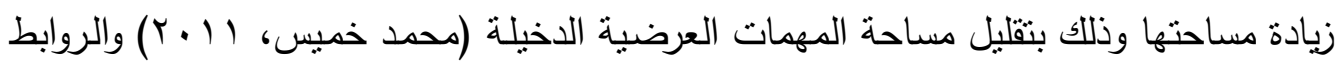

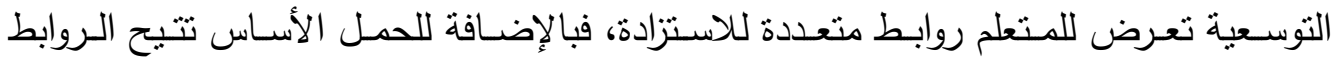

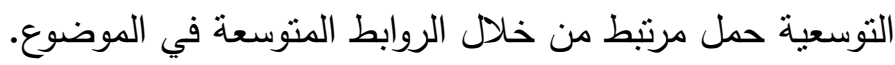


ويؤيد هذا التوجه أيضا نظرية الدافعية Motivation Theory فالدافعية هي حالة من الاهتمام والرغبة والنشاط الملحوظ في سلوك الفرد، نتيجة لواعث داخلية أو خارجية، تدفع هذا

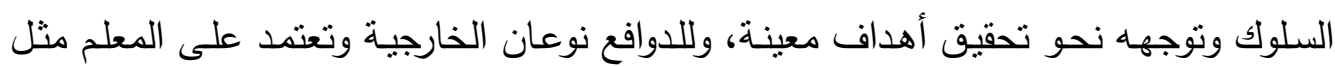

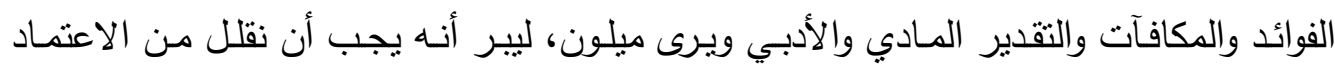

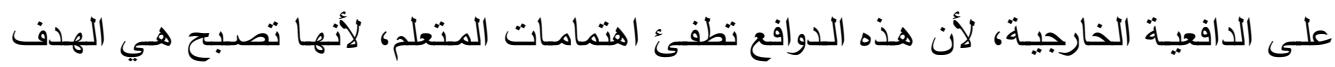

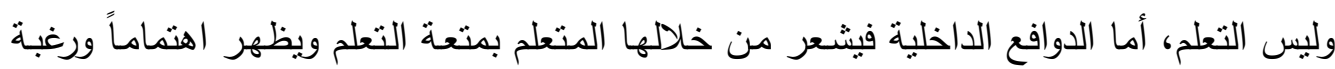

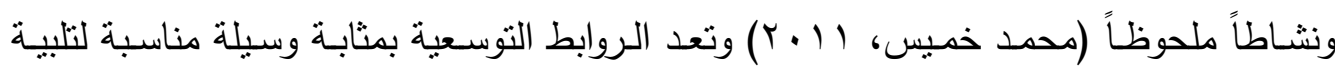

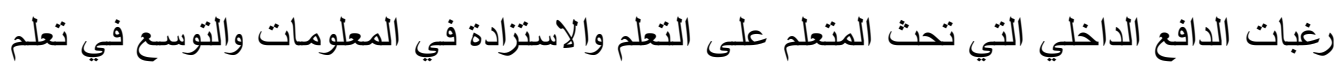
المحتوى بالوصول لأكثر من رابط.

Connectivism ومن النظريات التي تدعم الروابط التوسعية أيضاً النظريـة الاتصالية Theory

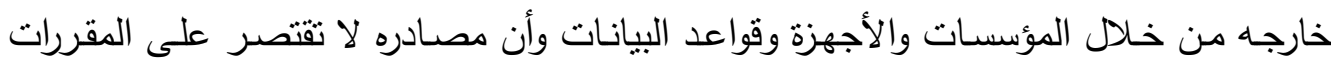

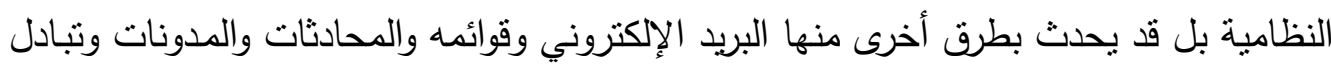

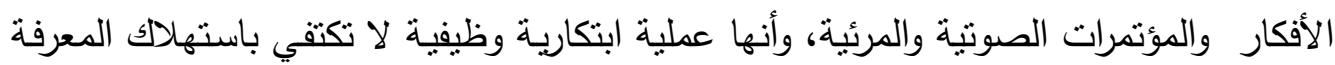

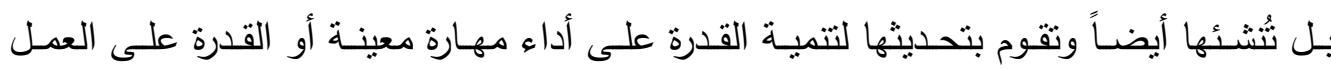

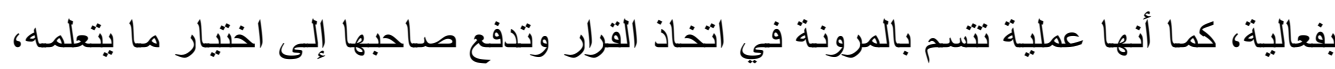

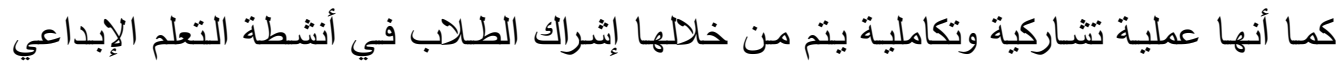

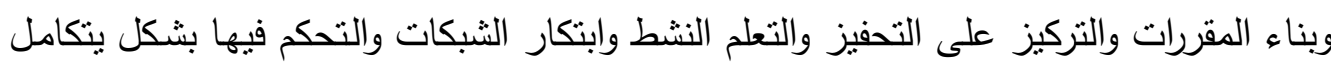

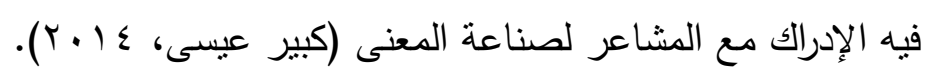

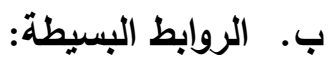

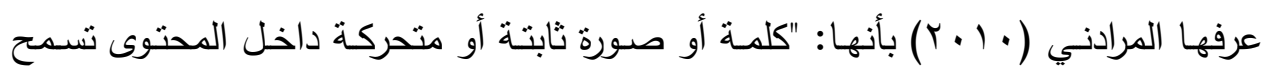

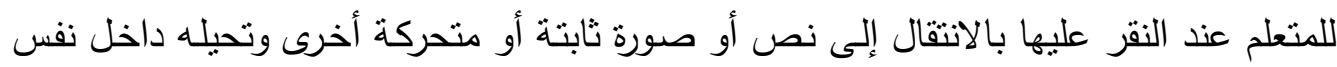

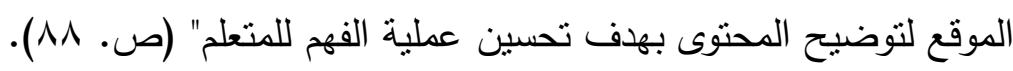

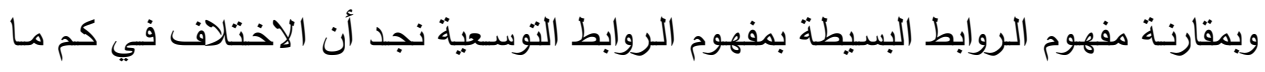

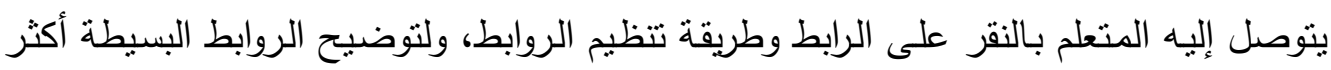

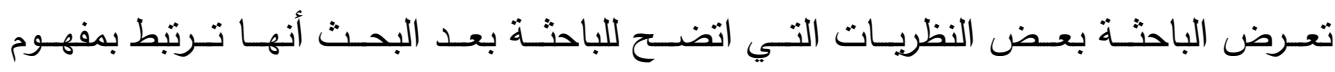
الروابط البسيطة.

وبداية تتطرق الباحثة للنظرية والمدخل السلوكي وهو من أكثر المداخل شيوعاً في تصميم

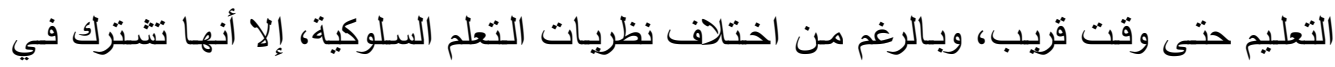


مبادئ أساس، تستخدم في تصميم التعليم، وهي التحديد الدقيق للأهداف التعليمية، وتحديد نتابع

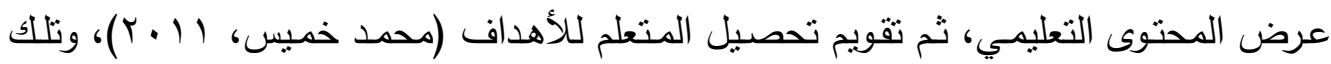

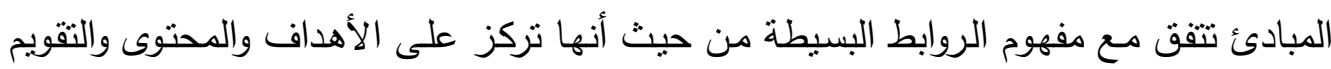

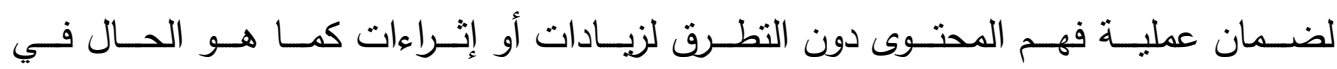
الروابط التوسعية.

وبالمرور على نظريـة معالجـة المعلومـات والتي تم توضيحها في الجزء الخاص بالروابط التوسعية فإن لها أيضاً شقاً يتلائم مع مفهوم الروابط البسيطة، حيث أن أنهات لهذه النظرية مفهومين

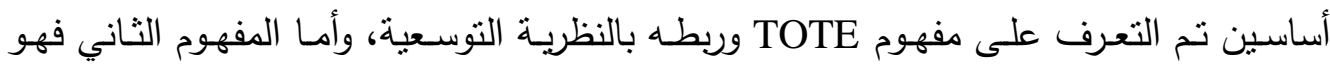

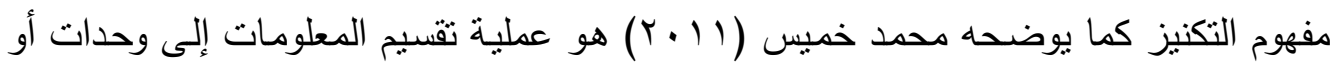

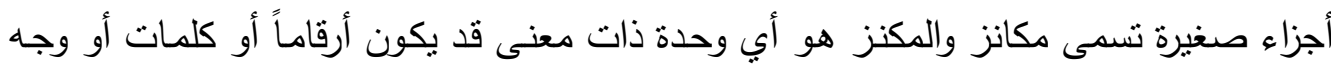

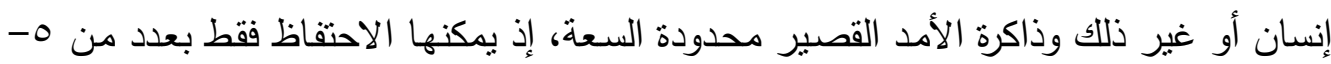
9 مكانز معلومات ويمكن زيادة سعة هذه الذاكرة وتسهيل عملية التذكر إذا تم تكنيز المعلومات.

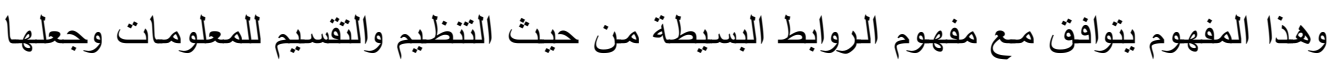

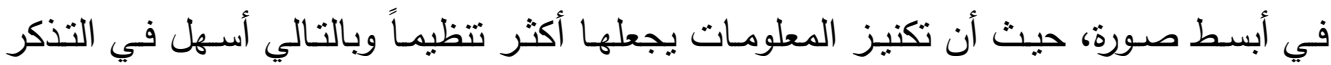
والفهم وبأبسط الطرق.

وعلى غرار نظرية معالجة المعلومات ومفهوم التكنيز ، فكذلك نظرية الحمل المعرفي والتي

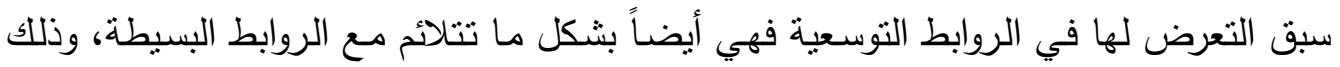

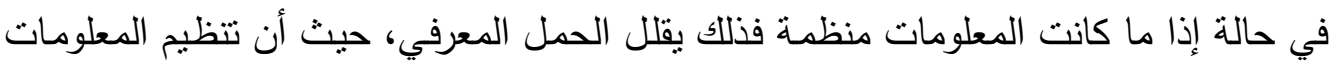

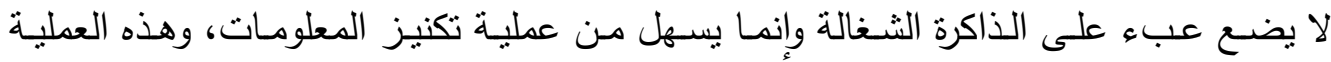

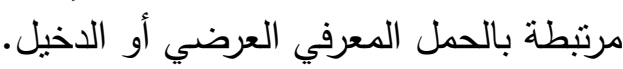

كما ترتبط نظرية الترميز الثنائي بنظرية معالجة المعلومات، وطبقاً لنظرية الترميز الثنائي

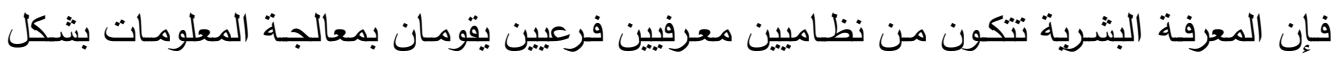

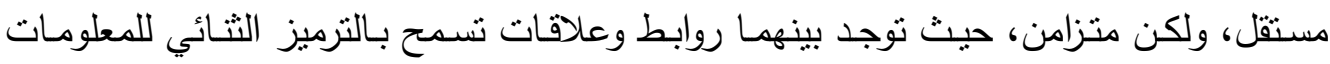
ولكل نظام وظائف مختلفة وعلى ذلك يميز بيفيو بين نولئ نوعين من وحدات المعالجة هما: 1- النظام اللفظي: ويعالج المعلومات اللفظية ويخزنها في الذاكرة حيث يقوم هذا لئن النظام بتوليد الكلام للكائنات اللفظية وتتظيمها في شكل ترابطات هرمية.

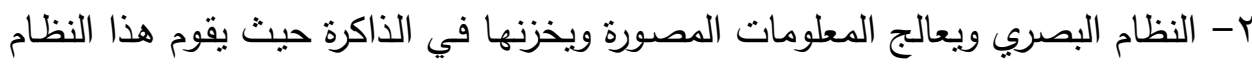
بتوليد الصور العقلية وتتظيمها في شكل علاقات بين الجزء والكل. 
وأثنتت البحوث أن تتظيم المعلومات اللفظية والبصرية يساعد على استبعاد المعلومات غير

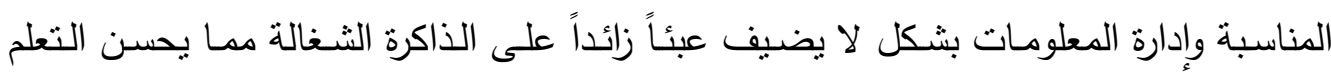

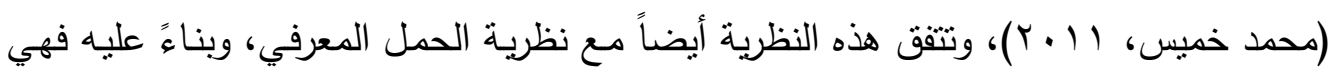
ترتبط بمفهوم الروابط البسيطة من حيث التنظيم والتحديد واستبعاد كل ما يجهد الذاكرة الثنغالة، وذلك للوصول لفهم أفضل للمحتوى.

\section{مميزات روابط المحتوى ومبادى \& إنشائها:}

من مميزات النص الفائق أنه لا يفرض على إنقاتها: المتعلم أسلوب المعلم في تتظيم المعلومات،

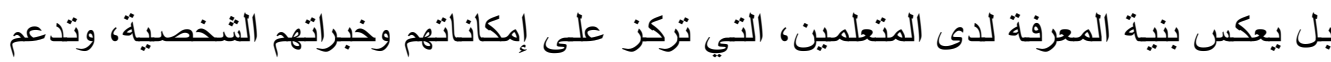
الأساليب الفردية التي يفضلها كل متعلم في النفاذ إلى المعلومات ومعالجتها، وتؤكد الدراسات التهات على أن تلك المزايـا يستثرها الطـلاب ذو مستوى الإنجاز العالي، ولديهم معرفة سـابقة عن فئن

$$
\text { المحتوى (هناء خضري، } 1 \text {... ب). }
$$

وتساعد الروابط المتعلم في تحقيق ما يلي:

- القدرة على تحديد تتبع المعلومات بشكل صحيح.

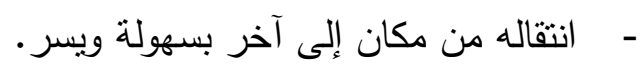

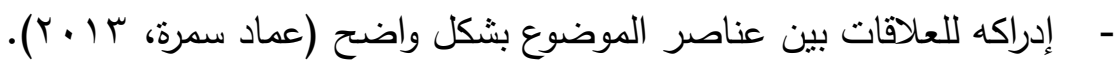
وتعد روابط المحتوى من أهم أدوات اكتساب المعلومات، فالبحث والتصفح من الأنشطة التي إني

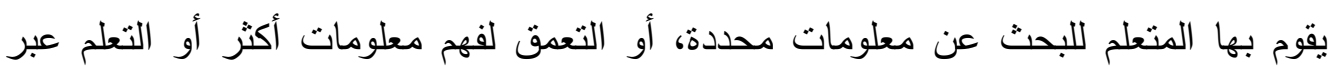

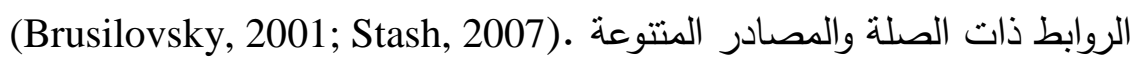
ويوجد مبادئ عدة لإنشاء روابط المحتوى هي:

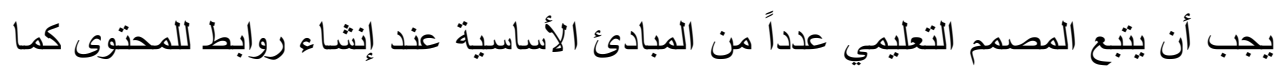

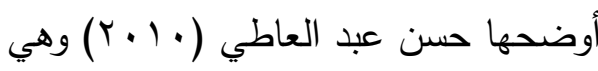

$$
\begin{aligned}
& \text { - التأكد من أن الروابط واضحة. } \\
& \text { - - أن تفحص الروابط مرة على الأقل كل فصل دراسي. }
\end{aligned}
$$

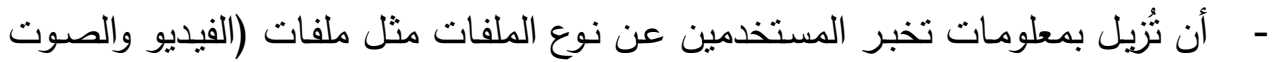

$$
\text { والنصوص والصور .. الخ). }
$$

- - مراعاة أن تكون كل صفحة مرتبطة بالصفحة الرئيسية، وما قبلها من صفحات. - - تحديد روابط المواقع المتعلقة بالمقرر ، والتأكد من سهولة استخدامها. 
- - تحديث روابط المقرر بانتظام، وخاصة الروابط غير النشطة.

- - اختبار فاعلية الروابط من جانب المستخدمين المبتدئين وذوي الخبرة. - - يجب أن تصف أشكال الروابط الوظيفية الني تؤديها بحيث تناعد المتعلمين للانتقال

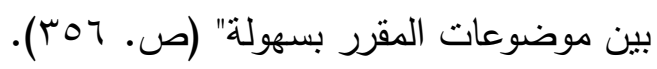

المحور الثالث: تنمية المهارات العملية وعلاقتها بروابط المحتوى (التوسعية - البسيطة)

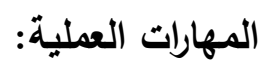
المهارة العملية كما عرفها محمد خميس (10 ب ب) هي: "تلك المهارات التي تتطلب تتاسق بين العين واليد أو القدم، كما هو الحال في تعلم مهارات الكتابة، وركوب الدراجة، وقيادة

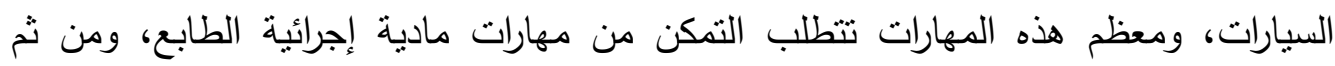

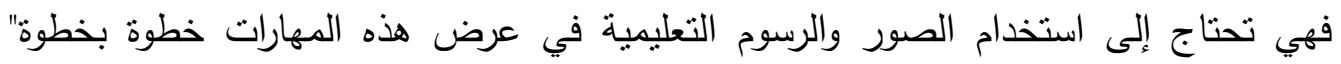
. (ص. (ص)

وتتتوع المهارات العملية بين مهارات يدوية، أكاديمية واجتماعية (زيد الهويدي، ه. . ب) وفي البحث الحالي ينم دمج جميع الأنواع حيث سيتم استخدام أدوات وأجهزة علمية وسينم

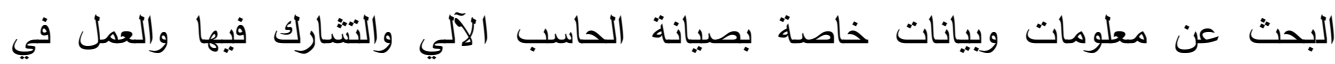
مجموعات تعاونية وهو من خصائص كتب الواقع المعزز حيث تدعم التعلم التعاوني كما ذكر فياته

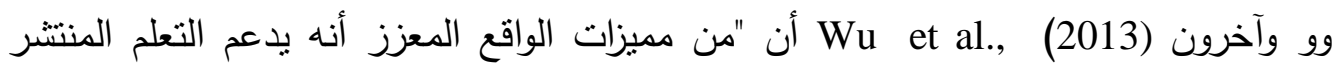

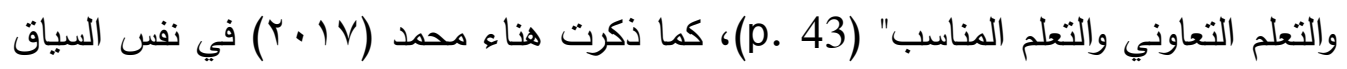

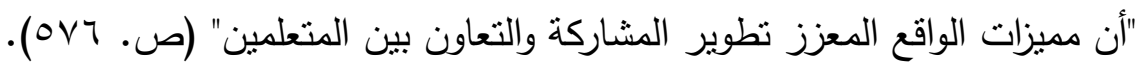
علاقة المهارات العملية بروابط المحتوى ( التوسعية- البسيطة): تتوعت الدراسات التي توضح علاقة المهارات العملية بروابط المحتوى ومنها دراسة عمادية التهاد

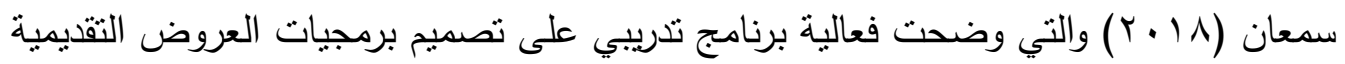

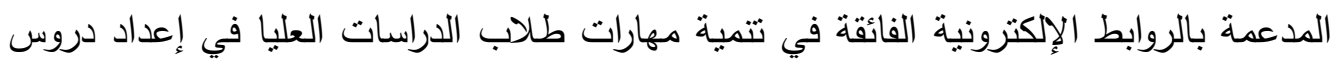
الرياضيات، وتكونت مجموعة البحث من طلاب الدراسات العليا تخصص الرياضيات الريات الملتحقين

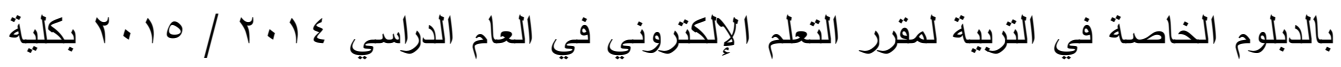

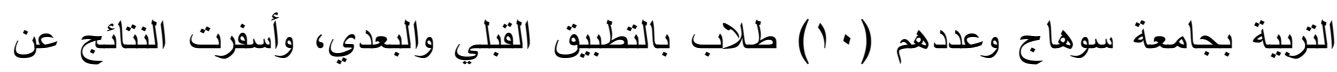

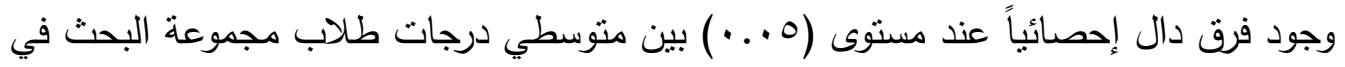

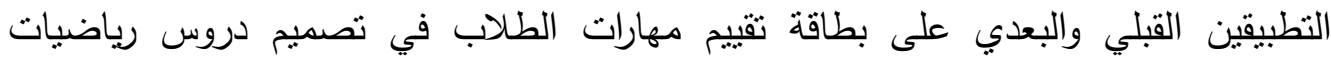

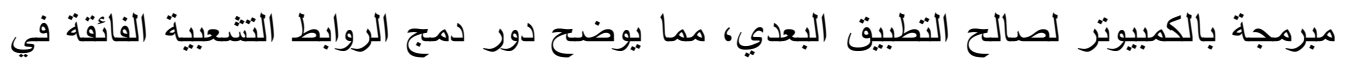

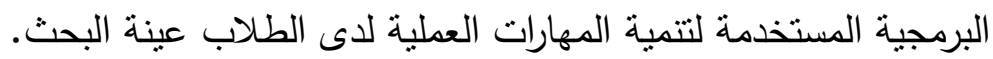




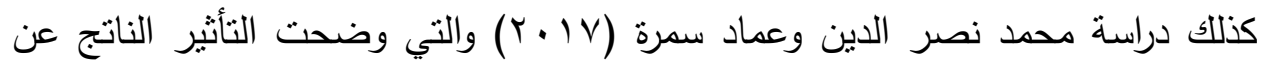

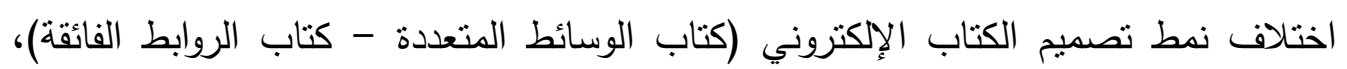

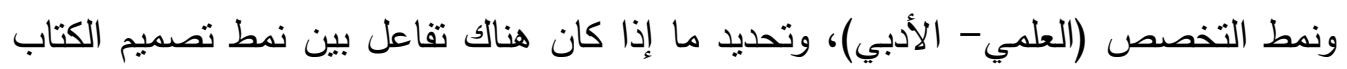

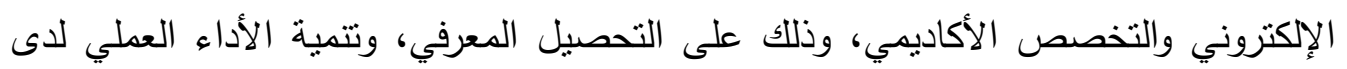

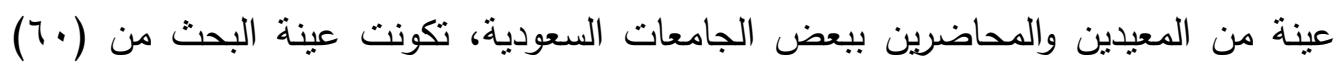

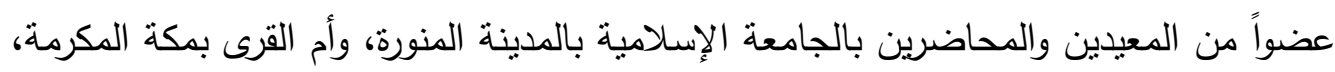
وتم تقسيمهم إلى أربع مجموعات تجريبية ضمت كل مجموعة (10) عضواً وفق التصميم التصنية التجريبي للبحث، وأسفرت النتائج عن وجود فرق دال إحصائيا عند مستوى (0. . •) بين درجات

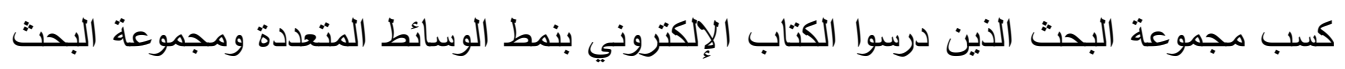
الذين درسوا الكتاب الإلكتروني بنمط الروابط الفائقة لصالح المجموعة التي درست لإنئ البرنامج بنمط تصميم الكتاب بالروابط الفائقة، ويتضح بذللك دور الروابط الفائقة في تتمية الأداء العملي.

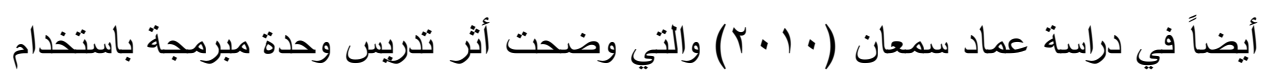

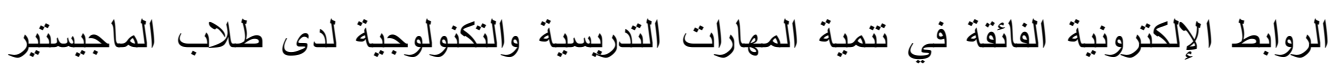

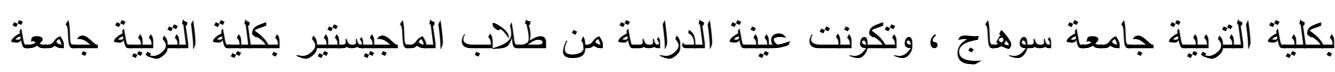

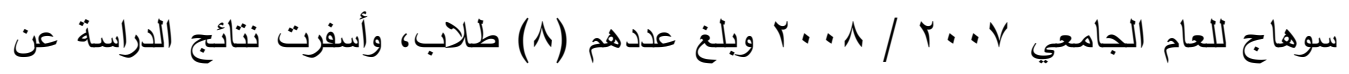

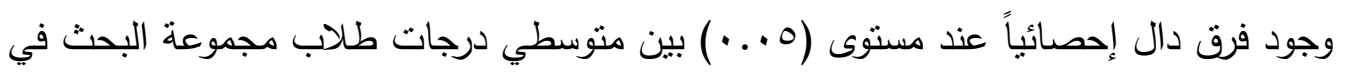

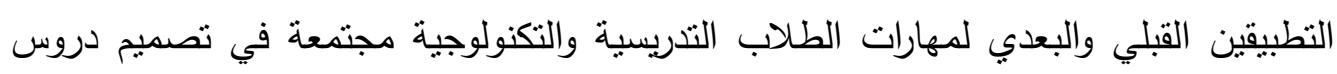
مبرمجة بالكمبيوتر لصالح التطبيق البعدي، وكذلك وضدت البعت النتائج وجود فرق دال إحصائئاً

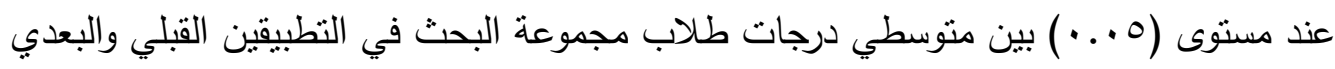

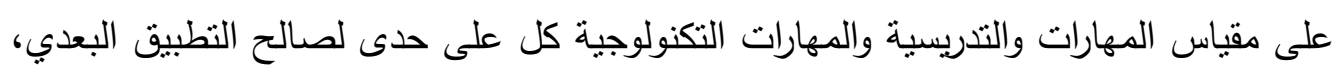
مما يوضح أيضاً تأثثر الروابط الإكترونية الفائقة في تتمية مختلف النهات المهارات. توضح الدراسات السابقة أهمية روابط المحتوى في تتمية أنواع مختلفة من المهابة المهارات

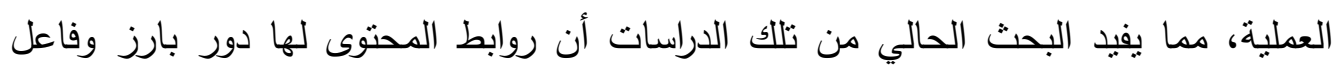

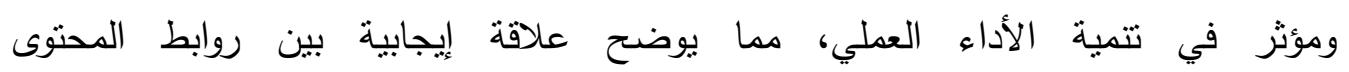
والمهارات العملية.

وعن البحث الحالي تتصور الباحثة أن الروابط التوسعية تقيد في عرض المهارة العملية

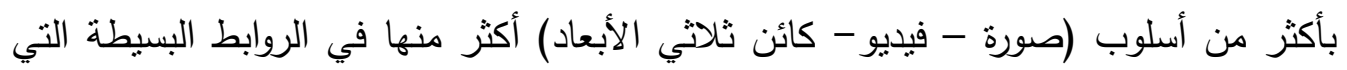
تقتصر على نوع واحد من أساليب عرض المحتوى (صورة - فيديو - كائن ثناثي الأبعاد).

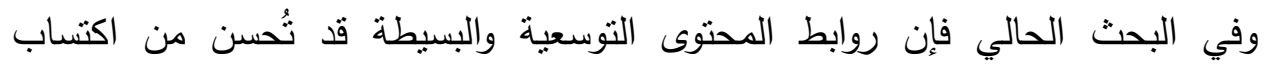


توصل البحث الحالي إلى عدة نتائج أهمها:

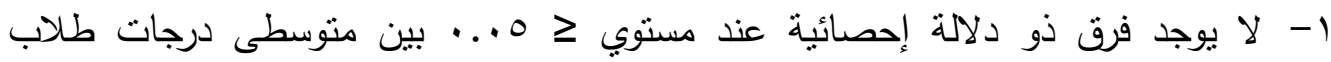

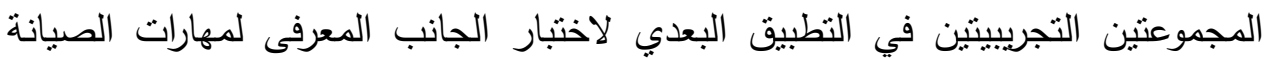

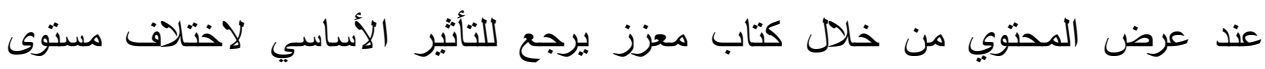

$$
\text { الروابط (توسعية/بسيطة). }
$$

يتضح عدم وجود فروق في التحصيل المعرفي ترجع إلى مستوى روابط المحتوى (التوسعية - البسبطة) حيث قيمة ف غير دالة إحصائياً وأن قيم المتوسطات منقاربـة فئ والفروق بينها

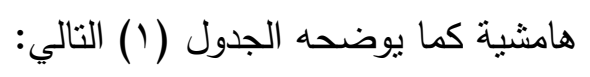

\begin{tabular}{|c|c|c|c|c|}
\hline الالمراف & الحتوسط الحسبي & العدد & (التوسعية - البسيطة روابط المحتوى) & الاختبار \\
\hline 8.118 & 59.09 & 22 & توسعي & \multirow[t]{2}{*}{ التحصيل المعرفي } \\
\hline 8.240 & 57.00 & 22 & بسيط & \\
\hline
\end{tabular}

جدول(1) الإحصاءات الوصفية لدرجات المجموعنين في النطبيق البعدي (التحصيل المعرفي)

مما يعني قبول الفرض الصفري الذي يعني عدم وجود فروق ترجع للتأثير الأساسي لاختلاف

$$
\text { مستوى الروابط (توسعية - بسيطة). }
$$

r- لا يوجد فرق ذو دلالة إحصائية عند مستوي \ 0... بين متوسطى درجات طلاب

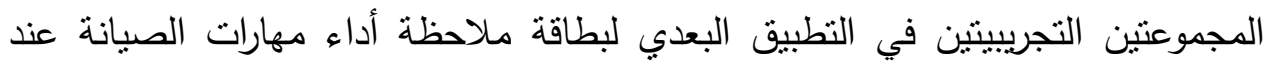

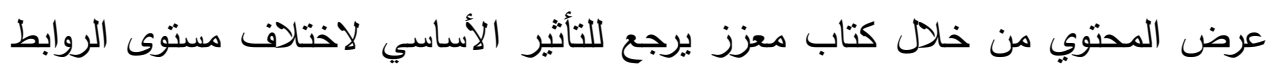

$$
\text { (توسعية/ببيطة). }
$$

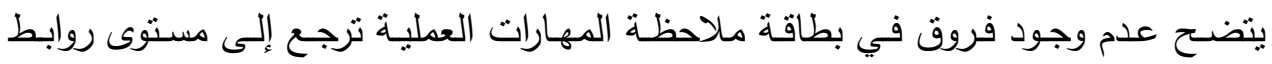

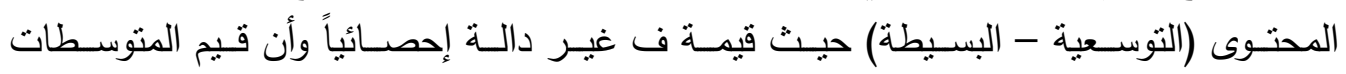

\begin{tabular}{|c|c|c|c|c|}
\hline الالمعراف & الحسابي & العدد & (التنوسعية - البسيطة) المحتوى & الاختبار \\
\hline 5.061 & 130.23 & 22 & توسعي & بطاقة ملاحظة \\
\hline 5.821 & 132.55 & 22 & بسيط & لمهارات العملية \\
\hline
\end{tabular}
للمجموعات الأربعة منقاربة والفروق بينها هامشية كما يوضحه الجدول (r) التنالي: جدول(ץ)الإحصاءات الوصفية لدرجات المجموعتين في النطبيق البعدي

(بطاقة ملاحظة المهارات العملية) 
مما بعني قبول الفرض الصفري الذي يعني عدم وجود فروق ترجع للتأثنر الأساسي لاختلاف مستوى الروابط (توسعية/ببسيطة).

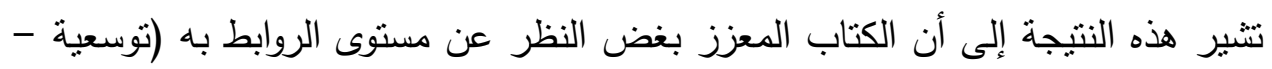

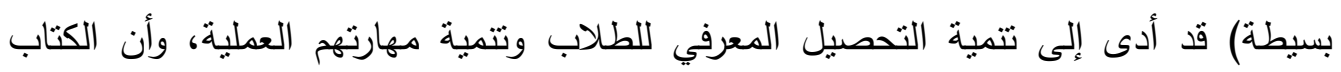

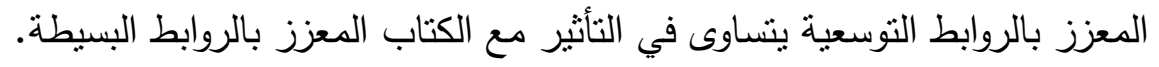
ومن خلال ملاحظة الباحثة للطلاب أثناء التجربة، لاحظت الباحثة أن الطلاب الدارسين بالروابط التوسعية ينفذون الأنشطة في مواعيدها وبصورة صحيحة كما يفعل الطلاب الدارسين

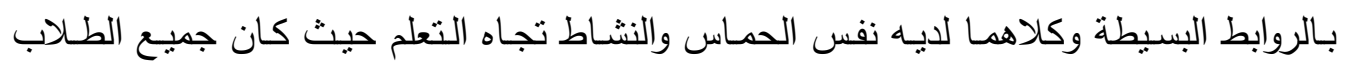

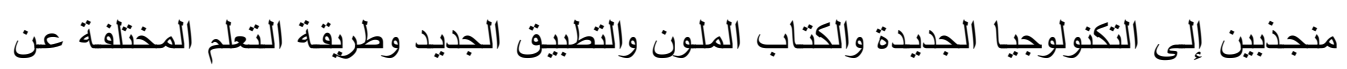
الدراسة العادية فكان الدارسين بالروابط التوسعية والروابط البسيطة دون فرق بينهم. وهذا ما تشير إليه البحوث من حيث فاعلية الكتاب المعزز وأنه تكنولوجيا شيقة وممتعة

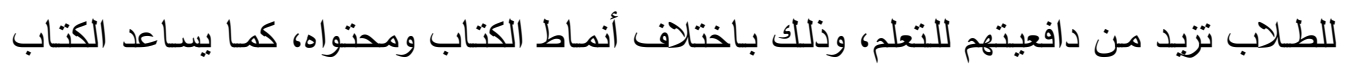

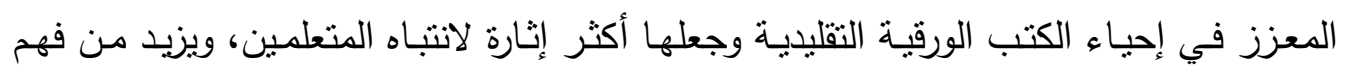

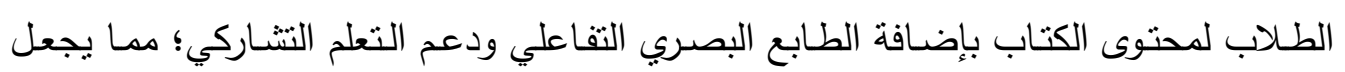

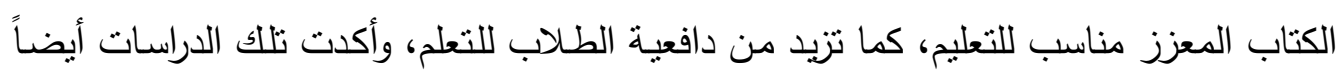

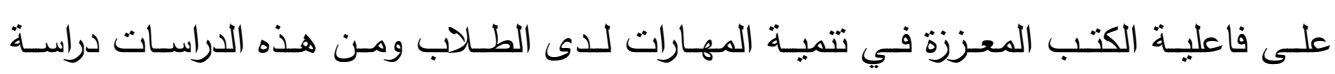
Darmawiguna et al., 2015

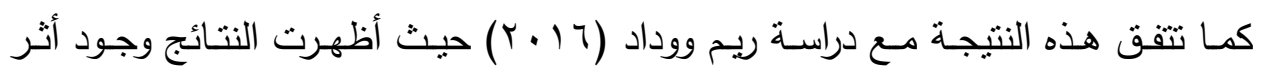
إيجابي للتدريس باستخدام تقنية الواقع المعزز في تتمية التحصيل الدراسي والدافعية حيث تثيح هذه التقنية الفرصة لعرض المحتوى بطريقة مختلفة عن النمط التقليدي. وكذلك في دراسة عباس وزمان Abas \& Zaman (2011) حيث ذكروا بدراستهم دراسة تخص الكتاب المعزز في التعليم، ووضحوا أن الكتاب المعزز أداة تعليمية فعالة تجعل وركل التعلم أكثر متعة وجاذبية كما تعطي الدافعية للطلاب من خلال تفاعلهم مع محتويات الكتاب. وفي دراسة يوسف وآخرون (2015) (أكدوا على أن استخدام تكنولوجيا الواقع المعزز تسهم في تعزيز جذب انتباه الطالب من خلال مفهوم كتاب الواقع المعزز • كما يمكن تفسير هذه النتيجة في ضوء النظريات التي تدعم فكرة التعلم بالواقع المعزز،

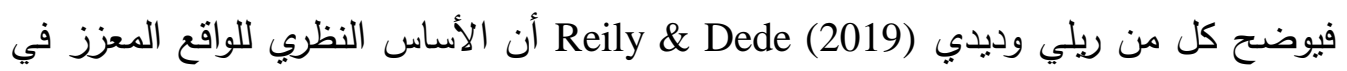


التعليم يمكن توضيحه بنظريتين وهما البنائية الاجتماعية Social Constructivism ونظرية التعلم القائم Situated Learning Theory؛ حيث نوضح توضئه النظرية البنائية الاجتماعية أن التعلم لا يحدث من فراغ، وأن المعرفة الجديدة ثُنىى على المعرفة السابقة التي تم اكتسابها في بيئات

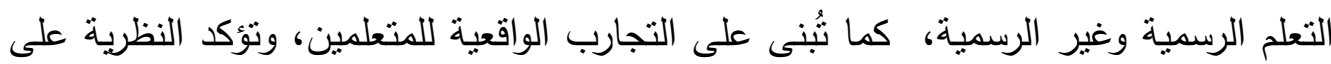
تفاعل الأفراد داخل الفصول أو المجموعات، حيث لا بمكن اعنبار الأفراد منعزلين، فالأفراد

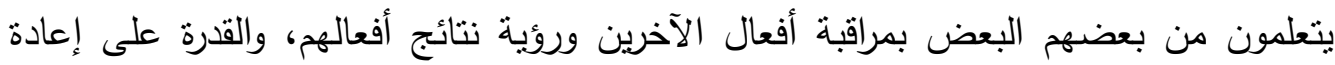

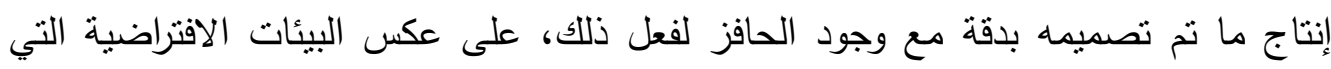

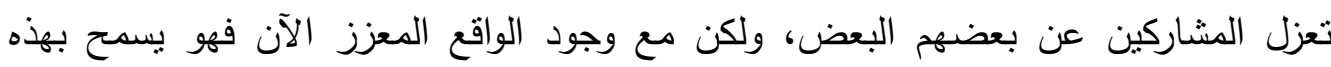

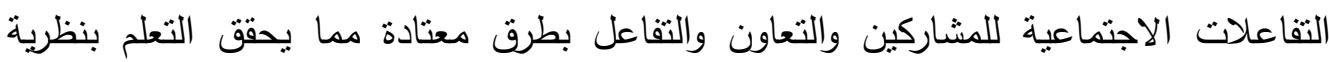

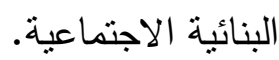

أما عن نظرية التعلم القائم فتوضح أن التعلم يحدث في سياق مادي واجتماعي أيضاً،

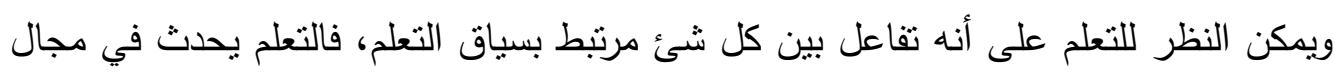

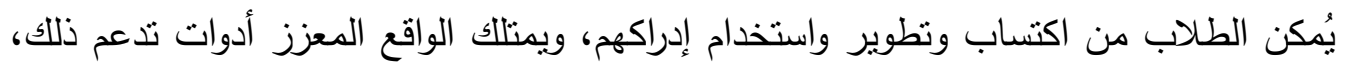

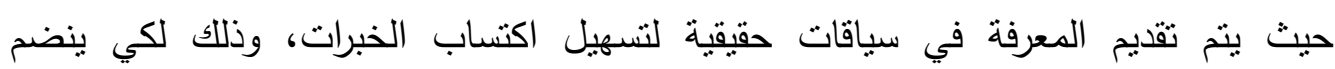
المتعلمون إلى مجتمعات الممارسة التي تحاكي المجتمعات الخاصة بالخبراء.

كما توضح نظرية المعلومات المعرفية Cognitive Information Theory هذه النتيجة من موضع آخر ، حيث تقوم النظرية على فكرتين أساسيتين لمعالجة المعلومات وهما التقسيم

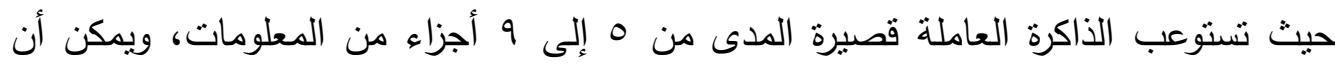
تشير هذه الأقسام إلى رقم أو كلمة أو موضع قطعة شطرنج أو وجه شخصة المّاء أما الجزء الثناني

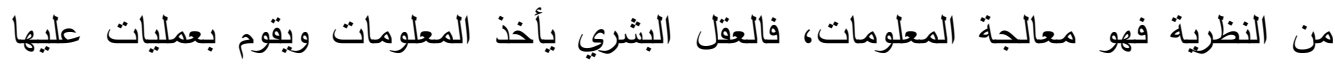

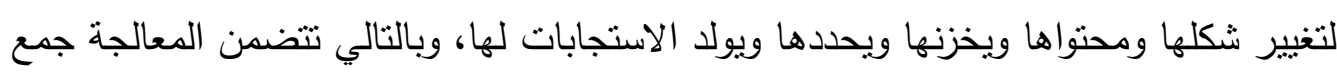

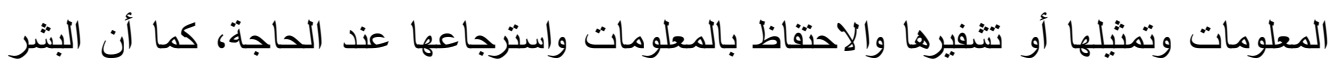
يتعلمون أكثر بعمق من الكلمات والصور أكثر من الكلمات وحدها فيما يعرف بمبدأ الوسائط

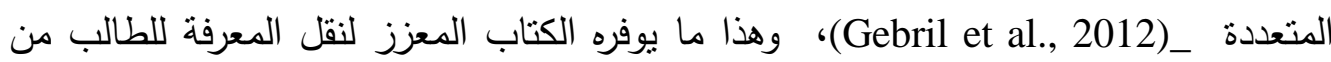
خلال الوسائط التعليمية المتعددة من صور وفيديو وكائنات ثلاثية الأبعاد بطريقة شيقة ومثيرة وجذابة وأكثر فاعلية من كون الكتاب نصوص جامدة دون صور أو فيديو أو كائنات ثلاثية الأبعاد. 
في ضوء ما أسفرت عنه نتائج البحث الحالي نوصى الباحثة بما يلي:

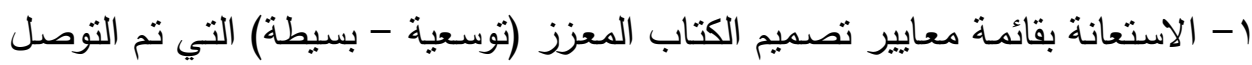

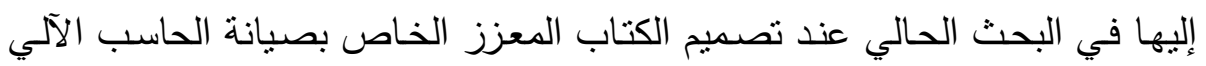

$$
\text { بمستوى الروابط (توسعية - بسيطة). }
$$

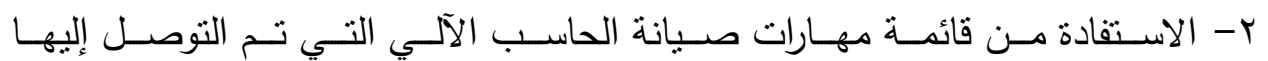
بالبحث الحالي.

r- يمكن الاستفادة من دمج الروابط التوسعية والبسيطة بكتاب معزز واحد حيث من نتائج البحث لا توجد فروق ذات دلالة إحصائية بينهما.

ع - تفعيل إنتاج الكتب المعززة بكليات التربية النوعية.

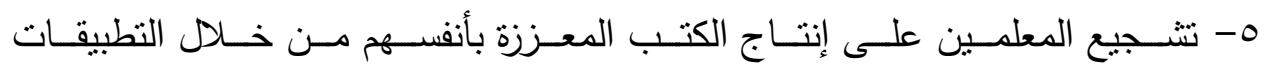
المجانية المتاحة.

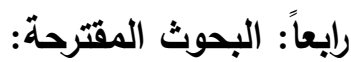

في ضوء النتائج التي نم التوصل إليها نقترح الباحثة إجراء الموضوعات البحثية التالية: 1- اختلاف تتظيم المحتوى في كتب الواقع المعزز وأثزه على تتمية المهارات العملية.

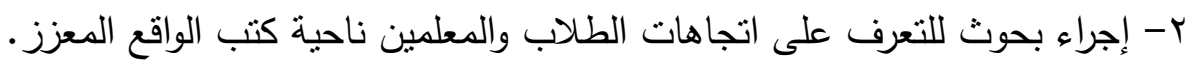
r- اختلاف أنماط الدعم في كتب الواقع المعزز وأثنره على تتمية المهارات العملية.

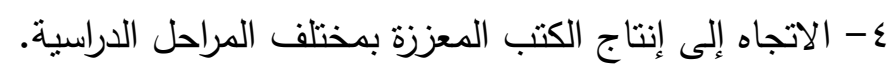

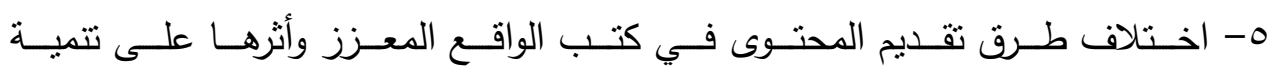
المهارات العملية.

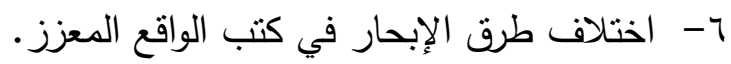
- - دراسات تحليلية ووصفية لكتب الواقع المعزز - V 
Garzon, J; Kinshuk; Baldiris, S; Gutierrez,J; \& Pavon, J. (2020). How do pedagogical approaches affect the impact of augmented reality on education? A metaanalysis and research synthesis.educational research review. $31,1-19$.

Lee, K. (2012, March/April). Augmented Reality in Education and Training. TechTrends, 13-21.

Tang, A., Biocca, F. \& Lim, L. (2004).Comparing Differences In Presence During Social Interaction In Augmented Reality Versus Virtual Reality Environments: An Exploratory Study Retrived 8/5/1435H ,3:30p ,from: http://s.v22v.net/JAP

cho, k., yoo, j., jung, j., \& yang, h. (2010). Multiple Page Recognition and Tracking for Augmented Books. In h. yang, r. malaka, j. hoshino, \& j. han, Entertainment Computing -ICEC 2010.(pp. 127-138). Heidelberg: Springer.

Dunser, A.,\& Hornecker, E.(2007). An Observational Study of Children Interacting with an Augmented Story Book. In Hui, et al. (Eds.), Technologies for ELearning and Digital Entertainment, Second International Conference, (pp.305-315). Springer-Varlag.

Brusilovsky, P.(2001). Adaptive Hypermedia.User Modeling and User-Adapted Interaction, Kluwer Academic Publishers, 11, 87-110.

Stash, N.(2007). Incorporating Cognitive/Learning Styles in a General-Purpose Adaptive Hypermedia System. Eindhoven:Technische Universiteit Eindhoven. Retrieved from http://alexandria.tue.nl/extra2/200710975.pdf.

Alessi, S., \& Trollip, S.(2001). Multimedia for learning : methods and development. ( $3^{\text {rd }}$ ed.). Allyn and Bacon.

Tsandilas, T.(2003). Adaptive Hypermedia and Hypertext Navigation: Research Review for Depth Oral Examination. Dept. of Computer Science, University of Toronto, Retrieved from http://insitu.lri.fr/ fanis/docs/Depth.pdf.

Ko, S., \& Rossen, S.(2008).Teaching online: a practical guide. $\left(2^{\text {nd }} e d.\right)$, Routledge.

Deitel, P., \& Deitel, H. (2008). Internet \& World Wide Web:How to program: How to program series. $\left(4^{\text {th }}\right.$ ed.) Upper Saddle River, New Jersey: Pearson Prentice Hall.

from http://www.just.edu.jo/ qabuein/courses/cis340/Internet_How_to_Program_ 4th.pdf.

Conklin, J. (2002). Making Sense of Fragmentary Information: Compendium and the Intelligence Community [Doctoral dissertation, CogNexus Institute] https://www.researchgate.net/profile/Jeff

Conklin/publication/252175093_Making_Sense_of_Fragmentary_Informatio n_Compendium_and_the_Intelligence_Community/links/56411fdc08ae $24 \mathrm{~cd}$ 3e410344/Making-Sense-of-Fragmentary-Information-Compendium-andthe-Intelligence-Community.pdf.

Galitz, W. (2007). The Essential Guide to User Interface Design: An Introduction to GUI Design Principles andTechniques, ( $3^{\text {rd }}$ ed.), Wiley Publishing, Inc.

Wang, X., Tan, B., Shakery, A., \& Zhai, C.-X.(2009). Beyond Hyperlinks: Organizing Information Footprints in Search Logs to Support Effective Browsing. In CIKM(pp. 1237-1246), November 2-6, Retrieved from http://sifaka.cs.uiuc.edu/czhai/pub/cikm09-map.pdf 
Spiro, R., Feltovich, P., Jacobson, M., \& Coulson,R. (2004).Knowledge representation, content specification, and the development of skill in situation-specific knowledgeassembly: some constructivist issues as they relate to cognitiveflexibility theory and hypertext. Educational technology, 31(9). 22-25.

Stecher, B. (2010). Performance Assessment in an Era of Standards-Based Educational Accountability. Stanford, CA: Stanford University, Stanford Center for Opportunity Policy in Education.

خميس، محمد عطية (2013). النظرية والبحث التربوي في تكنولوجيا التعليم. دار السحاب.

Hsiao, K.,\& Chen, N.(2011, September). The Development of the AR-Fitness System in Education. In M. Chang, W. Hwang, M. Chen, \& W. Muller (Eds.), Educational Games and Virtual Reality/Augmented Reality Applications Edutainment Technologies, Springer. Doi: 10 .1007/978-3-642-23456-9.

Wu, H., Lee, S., Chang, H \& Liang, J.(2013). Current status, opportunities and challenges of augmented reality in education. Computers \& Education,62, 41-49.

Rodgers,C.(2014,July). Augmented Reality Books and the Reading Motivation of Fourth-Grade Students [Unpublished Doctoral dissertation, Union University].

Taketa, N., Hayashi, K., Kato, H., \& Noshida, S. (2007). Virtual Pop-Up Book Based on Augmented Reality. G. Salvendy, \& M. Smith, Eds. Human Interface(2), pp. $475-484$.

Yusoff, Z., Dahlan, H., M., \& Abdullah, N., (2015). Integration of Mobile Based Learning Model Through Augmented Reality Book by Incorporating Students Attention Elements. In H. A. Sulaiman, M. A. Othman, M. F. I. Othman, Y. A. Rahim, \& N. C. Pee (Eds.), Advanced Computer and Communication Engineering Technology, International Conference on Communication and Computer Engineering,(pp.573-584). Springer, Doi: 10.1007/978-3-319-07674-4.

Inagawa, N., \& Fujinami, K. (2008, July). Making Reading Experience Rich with Augmented Book Cover and Bookmark. Computer-Human Interaction, 157166.

Rahman, A., Alam, K., \& El-Saddik, A. (2011). Augmented HE-Book: A Multimedia Based Extension to Support Immersive Reading Experience. Autonomous and Intelligent Systems . 321- 330. springer.

Abas, H., \& Zaman, H. (2011). Visual Learning through Augmented Reality Storybook for Remedial Student. In Zaman, et al (Eds.), Visual Informatics:Sustaining Research and Innovations, Second International Visual Informatics Conference, 157-167. doi: 10.1007/978-3-64-2-25200-6.

Mart1'n-Gutie' rrez, J., Saor1'n, J., Contero, M., Alcan iz, M., Pe' rez-Lo’ pez, D., \& Ortega, M. (2010). Design and validation of an augmented book for spatial abilities development in engineering students . Computers \&Graphics . 7791.

Yuen, S.; Yaoyuneyong, G.;\& Johnson, E. (2011). Augmented reality: An overview and five directions for AR in education. Journal of Educational Technology Development and Exchange, 4(1), 119-140. 
أحمد شوقي، داليا. (2019). التفاعل بين أسلوب عرض الكائنات الرقمية (التجاور/ الإحلال)

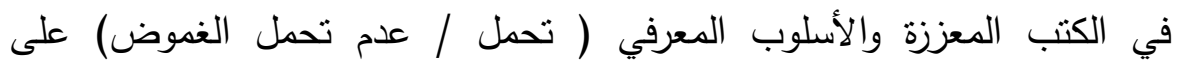
التحصيل الفوري والمرجأ والاتجاه نحوها لدى تلاميذ المرحلة الإعدادية. الجمعية المصرية لتكنولوجيا التعليم، 29 (1)، 3-114.

نصر ، نرمين، ومبارك، هدى.( 2017). أثز تطبيق الواقع المعزز في تتمية المهارات الأساسية

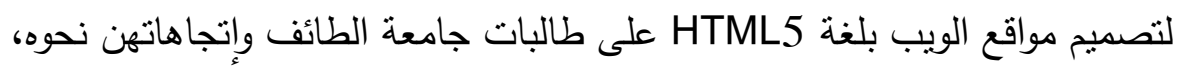

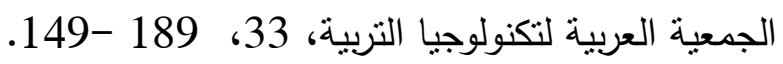

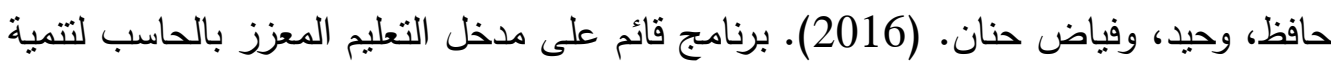

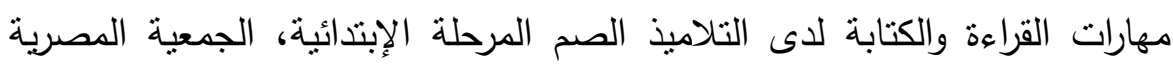
للمناهج وطرق التدريس، 216، 15 -132.

عبد القادر، فاطمة. (2018). فاعلية استخدام وحدة تعليمية قائمة على تقنية الواقع المعزز في

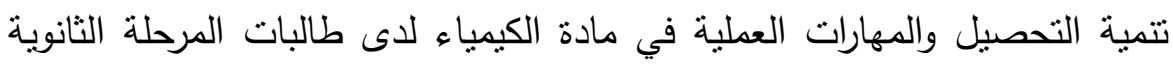
[رسالة ماجيستير ]. جامعة القصيم. محمد، عبد الحليم، عبد السلام، أحمد ، وإبراهيم، مجدي. (2018). فاعلية التعلم المقلوب

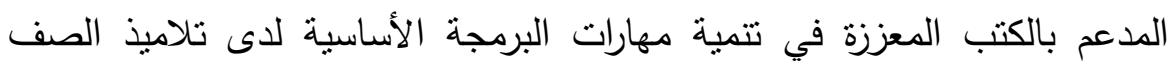
الأول الإعدادي، مجلة التربية، 2 (178)، 298 -330.

الدهاسي، الجوهرة. (2017). استخدام تقنية الواقع المعزز في تتمية مهارات التفكير الرياضي. مجلة القراءة والمعرفة، 190، 90-112، (112.

خليل، شيماء ـ( 2018). التفاعل بين تقنية تصميم الواقع المعزز ( الصورة / العلامة) والسعة

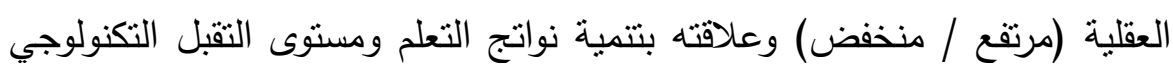
وفاعلية الذات الأكاديمية لدى طالبات المرحلة الثانوية. الجمعية العربية لتكنولوجيا

$$
\text { التربية، 36، }
$$

النخيلي، مروة. (2018). دمج تقنية الواقع المعزز مع الصحف المطبوعة كقيمة مضافة

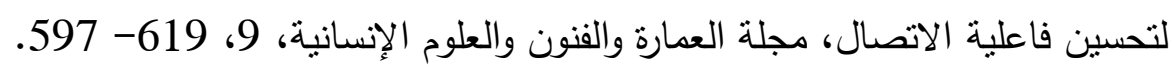
الغول، ريهام. (2016). تصميم بيئات التعلم بتكنولوجيا الواقع المعزز لذوي الاحتباجات

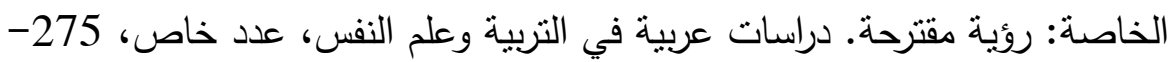


محمد، هناء. (2017). ثقنية الواقع المعزز وتطبيقاتها في عمليتي التعليم والتعلم. دراسات في

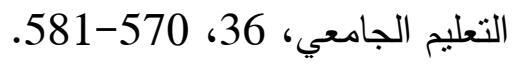

Kjellmo, I.(2013). Educational: 3D Design for Mobile Augmented Reality. In J.C. Anacleto et al. (Eds.), Entertainment Computing - ICEC 2013, 200-203.

Smith, M., Maiti, A., D. Maxwell, A., \& A. Kist, A. (2019). Using Unity 3D as the Augmented Reality Framework for Remote Access Laboratories In M. E. Auer and R. Langmann (Eds.), Smart Industry \& Smart Education, 581- 590.

الثنواني، هانيا. (2018). تقويم كتاب العلوم للصف الأول الابتدائى فى ضوء مواصفات 61الكتاب الددرسي الجيد، مجلة جامعة الفيوم للعلوم التربوية والنفسية، 9 (3)، 32-

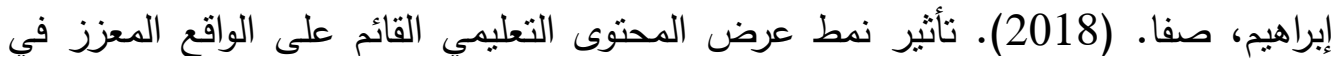

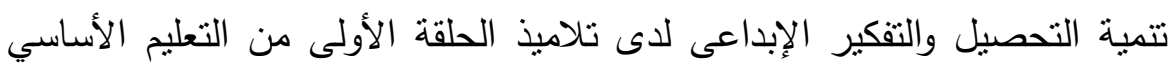
[رسالة ماجيستير غير منشورة]. جامعة حلوان.

Darmawiguna, G., Sunarya, M., Kesiman, M., Arthana, K., \& Crisnapati, P. (2015). The Augmented Reality Story Book Project: A Collection of Balinese Miths and Legends, In L. De paolis, \& A. Mongelli (Eds.), Augmented and Virtual Reality, Second International Conference, (pp.71-88). Italy: Springer, Doi: $10.1007 / 978-3-319-22888-4$

مرسي، الثيماء. (2018). اختلاف زاوية الروية بيئة الواقع المعزز شبه الانغماسية وأثرها فى الثي

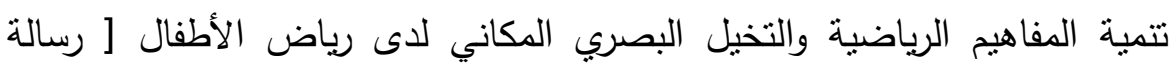
ماجيستير غير منشورة]. جامعة القاهرة.

خميس، محمد عطية (أ 2015). تكنولوجيا الواقع الافتراضى وتكنولوجيا الواقع المعزز

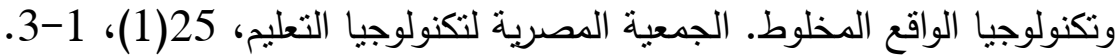
خميس، محمد عطية (ب 10 ب r). مصادر التعلم الإلكتروني الأفراد والوسائط: الجزء الأول.

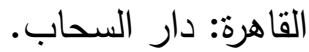

المرادني، محمد. (2010). أنز التفاعل بين أسلوب نقديم روابط المحتوى ونمط الإتاحة الالكترونية عبر الويب فى رفع كفاءة التعلم والدافعية نحو التعلم لدى التلاميذ

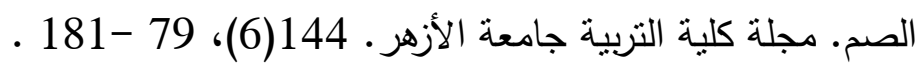

خميس، محمد عطية. (2011). الأصول النظرية والتاريخية لتكنولوجيا التعلم الإكتروني. دار

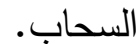

رشوان، إيمان. (2015). تصميم برنامج مقترح فى التربية الأسرية قائم على النظرية التوسعية وقياس فاعليته فى تتمية الوعى الاستهلاكي للمرأة المصرية. مجلة كلية كلية التربية

$$
\text { بأسيوط، 31 (5)، 295- } 352 .
$$


عبسى، بن كبير. (2014). آليات نوظيف النظرية الاتصالية في تعليمية اللغة العربية.

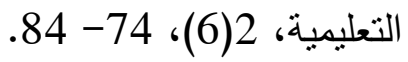

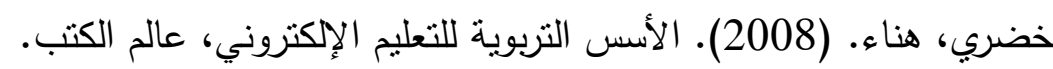

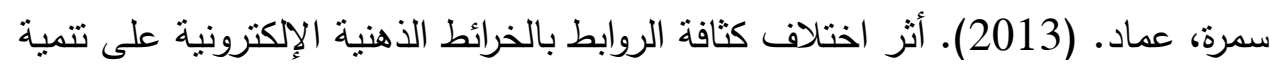

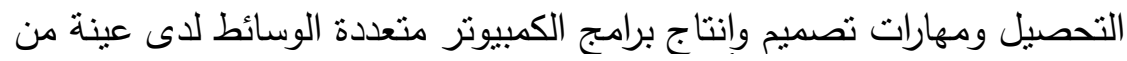

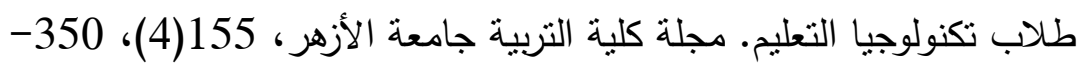
.400

عبد العاطي، حسن. (2010). التصميم التعليمى عبر الانترنت: من السلوكية إلى البنائية: نماذج وتطبيقات، دار الجامعة الجديدة.

الهويدي، زيد (2005). مهارات التدريس الفعال. دار الكتاب الجامعي.

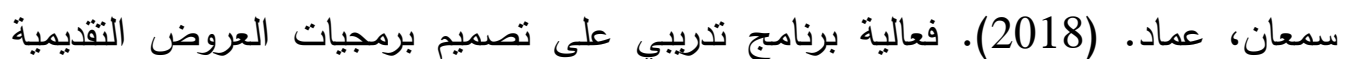
Power Point مهارات طلاب الدراسات العليا في إعداد دروس الرياضيات، الجمعية المصرية

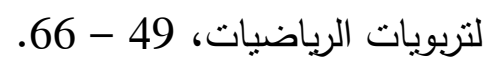

نصر الدين، محمد، وسمره، عماد. (2017). أثز التقاعل بين نمط تصميم الكتاب الالكترونى

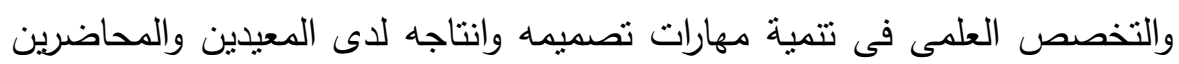

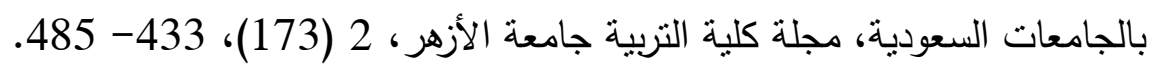

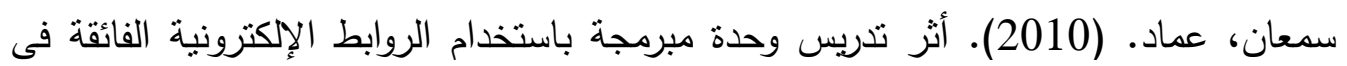

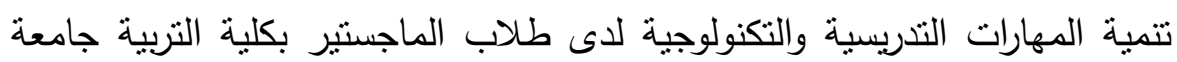

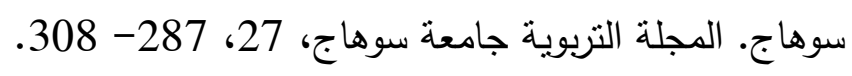

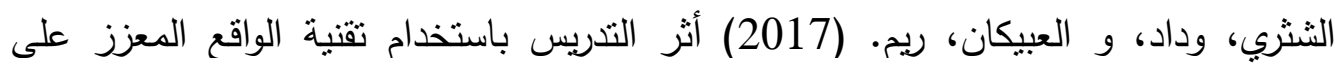

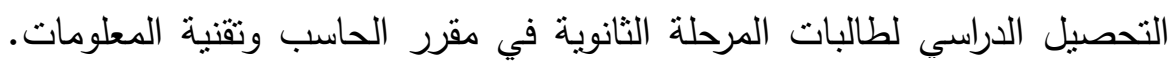

$$
\text { العلوم التربوية، } 4 \text { (1)، 139-173. }
$$

Reilly,J.,\& Dede,c.(2019). Augmented Reality in Education In Y. Zhang, D. Cristol (eds.), Handbook of Mobile Teaching and Learning, https://doi.org/10.1007/978-3-642-41981-2_126-1

Gebril,Z., Tele, I., Tahir, M., Parhizkar,B., ramachandran,A., \& Lashkari,A. (2012). Ubiquitous Medical Learning Using Augmented Reality Based on Cognitive Information Theory In D.C. Wyld et al. (Eds.): Advances in Computer Science, Eng. \& Appl., AISC 167, 305-312. 